NASA/TM-1998- 207310

\title{
AIAA 98-0882
}

Engineering Aerothermal Analysis for X-34 Thermal Protection

System Design

Kathryn E. Wurster,

Christopher J. Riley,

and E. Vincent Zoby

NASA Langley Research Center

Hampton, VA 23681

\section{6th Aerospace Sciences Meeting \& Exhibit January 12-15, 1998/Reno, NV}




\title{
ENGINEERING AEROTHERMAL ANALYSIS FOR X-34 THERMAL PROTECTION DESIGN
}

\author{
Kathryn E. Wurster*, Christopher J. Riley ${ }^{\dagger}$, and E. Vincent Zoby ${ }^{\dagger \dagger}$ \\ NASA Langley Research Center, Hampton, VA
}

\begin{abstract}
Design of the thermal protection system for any hypersonic flight vehicle requires determination of both the peak temperatures over the surface and the heating-rate history along the flight profile. In this paper, the process used to generate the aerothermal environments required for the $\mathrm{X}$ 34 Testbed Technology Demonstrator thermal protection system design is described as it has evolved from a relatively simplistic approach based on engineering methods applied to critical areas to one of detailed analyses over the entire vehicle. A brief description of the trajectory development leading to the selection of the thermal protection system design trajectory is included. Comparisons of engineering heating predictions with wind-tunnel test data and with results obtained using a NavierStokes flowfield code and an inviscid/boundary layer method are shown. Good agreement is demonstrated among all these methods for both the ground-test condition and the peak heating flight condition. Finally, the detailed analysis using engineering methods to interpolate the surface-heating-rate results from the inviscid/boundary layer method to predict the required thermal environments is described and results presented.
\end{abstract}

\section{Introduction}

Continued human presence in space will soon require upgrade or replacement of the current Space Transportation System. Joint NASA/industry partnerships have been formed to develop and test the technology required to provide cost-effective, yet reliable access to space. This is the primary goal of the Reusable Launch Vehicle (RLV) Technology Program. ' Development and flight of the suborbital X-34 vehicle is an integral part of the RLV program and is intended to address numerous operations, manufacturing, and other technology issues that can best be evaluated through demonstration on an actual flight vehicle. One of the key technologies to be demonstrated is that of an operationally effective thermal protection system (TPS). This paper describes the methodology by which the aerothermal environments for the X-34 are predicted in sufficient detail to allow design of the TPS such that the survivability, as well as the reusability, of the flight vehicle is ensured to a high degree of certainty. The primary focus of this paper is to describe how wind-tunnel and computational-fluids results have been coupled with engineering methods to predict the time-dependent thermal environments required for the design of the X-34 TPS.

*Senior Research Engineer, Vehicle Analysis Branch, Space Systems and Concepts Division. Member AIAA. ${ }^{+}$Research Engineer, Aerothermodynamics Branch, Aeroand Gas-Dynamics Division. Senior Member AIAA.

${ }^{+t}$ Senior Research Engineer, Aerothermodynamics Branch, Aero- and Gas-Dynamics Division. Fellow AIAA.

Copyright (O) 1998 American Institute of Aeronautics and Astronautics, Inc. No copyright is asserted in the United States under Title 17, U.S. Code. The U.S. Government has a royaltyfree license to exercise all rights under the copyright claimed herein for Governmental purposes. All other rights are reserved by the copyright owner.
Aerospace vehicles, such as the $\mathrm{X}-34$, that reach hypersonic speeds generally require protection of the vehicle structure from the aerodynamic heating at these conditions. TPS can be either of an active or a passive variety. Active systems typically use onboard coolant pumped through "pipes" behind the external surface or employ heat pipes which use capillary action to redistribute the heat from hot areas of the vehicle to cooler areas. A passive system, such as that employed on the X-34, takes advantage of the insulative properties of the TPS materials to hold a significant portion of the incident heat until it is radiated or convected away from the vehicle. The two critical parameters that determine the TPS options available for a given vehicle and trajectory are the peakheating rate and the integrated heating over the time of the flight profile. The former determines the maximum temperature environment, and thus the material options, and the latter determines the thickness distribution of the insulative TPS material required to protect the surface. Except for the nosecap and wing leading edges (where Silicone Impregnated Reusable Ceramic Ablator (SIRCA) $)^{2}$ tile is used), the $\mathrm{X}-34$ is protected with flexible-blanket or felt systems. At the request of the lead contractor, Orbital Sciences Corporation (OSC), the Langley Research Center ( $L a R C$ ) effort concentrated on the surface areas to be protected by the flexible systems. The flexible blanket and felt systems are described in detail in Ref. 3. Preliminary estimates of the heating to the stagnation areas will be included in this paper, but the bulk of the stagnation area analysis, both environment prediction and SIRCA tile design, has been performed at the Ames Research Center (ARC) and is described in Refs. 2 and 4. 
In the past, engineering methods have been used almost exclusively to predict external thermal environments and define TPS requirements for hypersonic flight vehicles. The advent of high-speed computers that reduce the time required to produce a computational solution has enabled incorporation of detailed flowfield methods much earlier in the design process. However, limited resources and the complexity of the typical vehicle configuration generally preclude the generation of a sufficient number of computational solutions to adequately define the heating histories for TPS definition. Similarly, the recent development of experimental wind-tunnel techniques, ${ }^{5}$ whereby heating distributions over the vehicle can be measured rapidly and at relatively low cost, also allows incorporation of experimental results at an early stage of the design process. These measured data are currently limited by the inability of the wind-tunnel to reproduce the actual flight environment (flight Reynolds numbers and reacting chemistry). Therefore, engineering techniques are used in this study to integrate the computational and the wind-tunnel results over the trajectory profile to provide the designers with sufficient information to adequately define the TPS requirements. The methodologies used to define the aerothermal environment and the process used in selection of trajectories will be described in this paper.

\section{Vehicle/Mission Description}

The X-34 Testbed Technology Demonstrator represents a key element of the RLV program. Originally envisioned as an operational vehicle with the capability to deliver relatively small payloads $(1000-2000 \mathrm{lb}$.) to low Earth orbit, the program was restructured in early 1996 to focus on demonstration of RLV technologies. ${ }^{6}$ OSC, formerly teamed with Rockwell International in the initial effort, ${ }^{7}$ was selected in June of 1996 to lead the redirected program. An artist's concept of the X-34

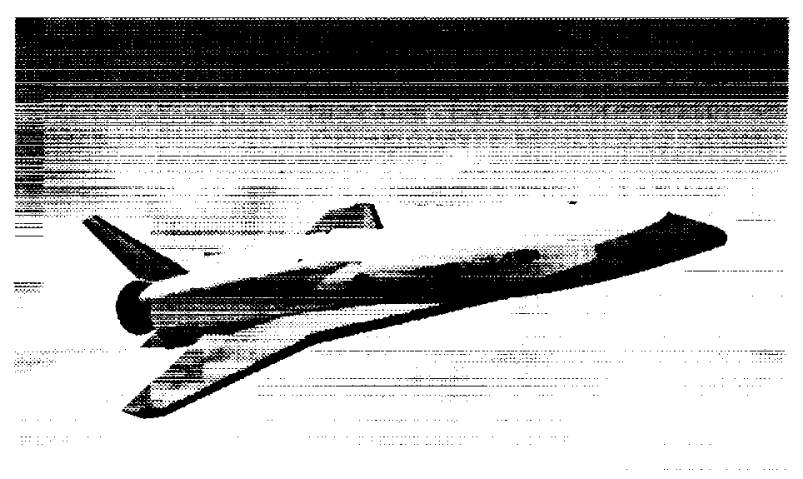

Fig. I Artist's concept of the $X-34$ configuration in flight.

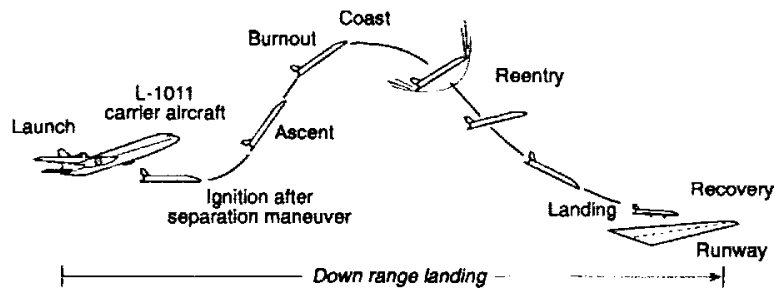

Fig. 2 Typical X-34 flight profile.

flight vehicle is shown in Fig.1. Compared to the Shuttle orbiter, the vehicle is relatively small with a length of $\sim 58 \mathrm{ft}$, a wing span of $\sim 28 \mathrm{ft}$ and a height (measured from the bottom of the fuselage to the tip of the vertical tail) of $\sim 12 \mathrm{ft}$. An illustration of a typical flight profile is shown in Fig. 2. The vehicle is designed to be airlaunched from an L-1011 at a Mach number of approximately 0.7, ignite its $60 \mathrm{klb}$ thrust bi-propellent (LOXJ kerosene) engine, accelerate to speeds up to Mach 8, reach altitudes up to $250 \mathrm{kft}$, and finally to coast to a horizontal landing on a conventional runway.

\section{Analysis Tools}

\section{MINIVER}

MINIVER $^{8}$ is a versatile engineering code that uses various well-known approximate heating methods, together with simplified flowfields and geometric shapes to model the vehicle. Post-shock and local flow properties based on normal-shock or sharp-cone entropy conditions are determined in MINIVER through user selection of the various shock shape and pressure options. The calculations can be based on perfect-gas or equilibrium-air chemistry. Angle-of-attack (AOA or $\alpha$ ) effects are simulated either through the use of an equivalent tangent-cone or an approximate crossflow option. ${ }^{9}$ The flow can be calculated for either two- or three-dimensional surfaces. However, the three-dimensional effects are available only through the use of the Mangler transformation ${ }^{10}$ for flat-plate to sharp-cone conditions. MINIVER has been used extensively as a preliminary design tool and has demonstrated excellent agreement with more detailed solutions for stagnation and windward acreage areas on a wide variety of vehicle configurations. ${ }^{11-14}$

\section{LATCH}

The Langley Approximate Three-dimensional Convective Heating (LATCH) code ${ }^{15}$ employs an inviscid/ boundary layer methodology that can be used to compute surface heating rates, both laminar and turbulent, on three-dimensional vehicles at AOA. An axisymmetric analog concept for three-dimensional boundary layers is used in conjunction with a generalized body-fitted coordinate system and an approximate heating method 
developed by Zoby. ${ }^{11,16,17}$ The LATCH code, using the method in Ref. 16, requires far less computational resources than a full boundary-layer solution. The LATCH method has previously been shown to provide accurate results for both wind-tunnel and flight conditions. ${ }^{15,18,19,20}$ An inviscid flow-field solution is used in the computation of boundary-layer edge properties and also to provide the surface velocities for computing the streamline directions. This method is described in detail in Ref. 15.

\section{Inviscid Solutions}

For the purpose of this study, the inviscid solutions required for use with the LATCH code are computed using either the Data-Parallel Lower-Upper Relaxation (DEPLUR) method ${ }^{21.22}$ or the Langley Aerothermodynamic Upwind Relaxation Algorithm ${ }^{23,24}$ (LAURA) run in the inviscid mode. These two codes, which take advantage of different computer architectures, allowed solutions to be run concurrently on different machines, generating a greater number of solutions than would have been possible using a single computer resource. Both codes utilize rectangularly-ordered structured grids as required for compatibility with LATCH. LATCH results for the peak heating condition computed using the DEPLUR and the LAURA inviscid solution are shown to be in good agreement, ${ }^{19}$ both with each other and with a detailed viscous thin-layer $\mathrm{N}$-S solution computed using LAURA. The LAURA viscous solution is described in detail in Ref. 25. Previous studies on a wide variety of vehicles including the Space Shuttle orbiter ${ }^{26}$, the Lockheed X-33 ${ }^{20}, \mathrm{HL}-20^{27}$, and Reentry- $\mathrm{F}^{28}$ have demonstrated the accuracy of the LAURA solutions computed for both flight and wind-tunnel conditions.

\section{Wind-Tunnel Test Techniques}

Advances in wind-tunnel test techniques have recently enabled the rapid acquisition of quantitative global heat-transfer measurements. The method, known as two-color relative-intensity phosphor thermography, is described in Refs. 5, 29, 30, and 31. Ceramic models, typically on the order of 12 in., can be fabricated rapidly, and a wide range of parametrics, including AOA, sideslip, Reynolds number $\left(\operatorname{Re}_{\infty}\right)$, Mach number $\left(M_{\infty}\right)$, and control surface deflections can be investigated. For the X-34 heating studies, ${ }^{32}$ results have been obtained using this technique in the Langley's 31-Inch Mach-10 and 20-Inch Mach-6 air facilities. These facilities are described in detail by Micol in Ref. 33. Digital optical measurements allow the rapid processing of data using Merski's IHEAT ${ }^{5}$ code. In addition to the global images available, spanwise and chordwise cuts can be presented for comparison with engineering or detailed solutions.

Flow visualization techniques are also used to complement the surface heating tests. ${ }^{32}$ The oil-flow tech- nique is used to highlight surface streamline patterns. A stainless steel model, painted black and coated with white pigmented oils, was tested in both the Mach-6 and the Mach-10 facilities. The Mach- 6 facility is equipped with a schlieren system which uses the density variation in the flowfield to highlight the existing shock patterns. These techniques, although qualitative in nature, represent an important contribution to the heat-transfer analyses by highlighting regions of the vehicle that may require detailed analysis.

\section{TPS Considerations}

OSC has chosen a TPS which utilizes thermal blankets over the acreage of the vehicle and ceramic tiles in the stagnation regions of the nose and the leading edges. This decision allows OSC to take advantage of a technology which has been demonstrated on the Space Shuttle orbiter, together with developments that have advanced these systems to improve the operational characteristics. A chief advantage of the flexible blankets is that they can be adhesively bonded to a non-smooth surface. Also, they should be fairly tolerant of the over temperatures that may be associated with heating uncertainties. However, the quilted-blanket design presents a fairly rough surface, and is more likely to induce turbulent flow than would a smooth surface. Also, use of blankets in areas of high shear stress has not been demonstrated. The TPS layout is shown in Fig. 3. Three types of blankets are utilized on the $X-34$ vehicle, depending on the peak temperatures expected. The first, Advanced Flexible Reusable Surface Insulation (AFRSI), is used for regions expected to experience temperatures no greater than $1500^{\circ} \mathrm{F}$. This blanket is flight certified and currently in use on the leeward regions of the Shuttle orbiter. As can be seen in Fig. 3, the second type of blanket is a High-Temperature AFRSI (HT-AFRSI) designed for reuse at temperatures up to $2000^{\circ} \mathrm{F}$. This blanket is used over the majority of the windward surface. In this blan-

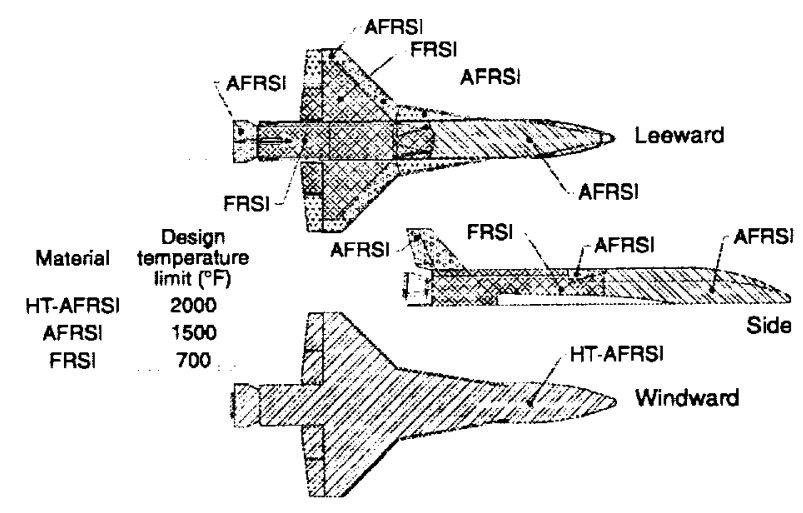

Fig. 3 X-34 TPS blanket layout. 
ket, the Astroquartz fabric and Q-felt insulation of the standard AFRSI are replaced with Nextel 440 and Saffil insulation, respectively, increasing its temperature capability. All blankets are assumed to be coated with Protective Ceramic Coating (PCC), a high-emissivity coating designed to improve radiant characteristics at high temperatures. Nomex Felt blankets, also known as Flexible Reusable Surface Insulation (FRSI), are to be used in the lowest temperature regions, up to $700^{\circ} \mathrm{F}$ (primarily the side fuselage and the upper surface). The blankets and coating are described in the Ames TPS materials portion of the TPSX Database. ${ }^{34}$ SIRCA $^{2}$ tiles are used in the high-temperature stagnation areas. Design and analysis for the tile regions was performed at ARC. ${ }^{2,4}$ The LaRC effort concentrated on the blanket areas of the vehicle. Areas of concern immediately noted were: roughness-induced turbulent heating, the design of the interface between the tile and blanket systems, potential areas of shock impingement and shock interactions, use of blankets in the high-dynamic pressure regions of deflected control surfaces, the zone of transition of the fuselage cross-section from circular to square, and the vortices which will likely emanate from the strake fuselage juncture.

\section{Overview of Aerothermal Approach for TPS Design}

This paper details the aerothermal environments prediction process as it has been applied to the X-34 effort. In the year and a half since LaRC began this effort, the thermal environment predictions have evolved from preliminary heating estimates limited to the stagnation areas and the windward centerline, to environments for eighty representative points on the vehicle, including offcenterline windward, leeward, and side fuselage locations. Prior to the acquisition of any wind-tunnel or computational data, a conservative engineering approach was employed. As wind-tunnel data became available, ${ }^{32} \mathrm{com}$ parisons were made with engineering predictions and the engineering model was refined to reduce the conservatism in the predictions. An approach that coupled the experimentally-measured heating distributions over the body with the time-dependent engineering predictions along the centerline was developed. This methodology was used to make the first predictions of the thermal environments over the acreage of the vehicle. The program schedule and computational resources limited the number of detailed Navier-Stokes (N-S) heating solutions that could be used to benchmark the engineering methods. Instead, a coupled inviscid/boundary layer method $^{19}$ was used. More points along the trajectory could then be computed because the inviscid/boundary layer method requires fewer computational resources than a N-S method. Inviscid solutions were coupled with an approximate heating method ${ }^{16}$ using the $\mathrm{LATCH}^{15}$ code to provide heating distributions over the surface of the vehicle. The inviscid solutions were chosen to bound the heating-rate, AOA, freestream Mach-number, and Reynolds-number ranges over the flight profile, including the peak heating condition. Finally, the engineering code, MINIVER, ${ }^{8}$ was used to interpolate the LATCHgenerated spatial distributions in Mach number, AOA, and Reynolds number over the time of the trajectory. Thus, the time-dependent thermal environments necessary for design of the flexible TPS to be used over the acreage of the vehicle could be predicted through an intricate integration of wind-tunnel, detailed computational, and engineering methods. The thermal environments generated in this manner have been used to define the TPS requirements for the $\mathrm{X}-34$ acreage areas ${ }^{3}$ protected by the flexible systems.

\section{Preliminary Aerothermal Predictions}

The first flight of the X-34 Technology Testbed Demonstrator is currently scheduled to occur prior to the end of 1998, approximately two and one-half years from the date of the award of the final contract In this remarkably short time frame, a vehicle system must be designed, materials ordered, components manufactured (including the engine which has yet to be demonstrated), ground facilities built, operational issues addressed, the vehicle assembled, the carrier aircraft modified, the vehicle mated, and ready to fly. The extraordinary pace of this program required that thermal environments be generated in parallel with design of the vehicle and development of the flight profile. The lead time required to set up for manufacture of the thermal blankets for the acreage and the tiles for the stagnation areas required preliminary definition of the TPS requirements very early on in the program. In light of these considerations, it was necessary to proceed with engineering estimates of the heating environments before any wind-tunnel data or detailed computations were available, and before a legitimate flight profile had been determined. A conservative engineering approach was therefore used for initial estimates. It was assumed that the conservatism in the design could be reduced as the fidelity of the models improved with introduction of additional wind-tunnel and computational results.

The MINIVER code has been shown to produce fairly accurate predictions of the time-dependent thermal environments for a variety of vehicle concepts, ${ }^{11-14}$ particularly for the windward surface regions and stagnation areas. Of course, the engineering techniques used will not predict localized flow phenomenon such as heating due to shock interactions or imbedded vortices. Ar- 
eas of potential concern were identified and recommended for detailed computational study or wind-tunnel testing as appropriate. The inherent roughness of the quilted blanket system coupled with the low-altitude, high-Reynolds-number flow regime led OSC to make the decision that the acreage TPS be designed for fully turbulent flow and heating levels. Langley concurred with this decision and, although some laminar calculations were performed to validate computational efforts, the environments provided for blanket design were all fully turbulent.

When simple engineering techniques are used, prediction of accurate thermal environments for a vehicle such as the X-34 is very much dependent on the experience of the thermal analyst and recognition of the limitations of the codes." The windward centerline calculations were performed assuming sharp-cone entropy conditions, flat-plate heating with the Mangler transformation used to correct for a three-dimensional boundary layer effects. When seen in cross-section, the windward surface of the X-34 vehicle is extremely flat. This, coupled with the low angle-of-attack trajectory profiles suggested limited crossflow effects and no crossflow correction was included in the initial heating estimates. As stated previously, all acreage environments were based on fully turbulent flow conditions.

The initial trajectory used was denoted "WAG18D", and is presented in terms of Mach number, altitude, and AOA in Fig. 4. A more detailed discussion of the trajectory development and analysis will be discussed in a later section. It should be noted however that, of all the trajectories examined, the WAG18D was found to be the most severe in terms of both heating rates and loads. A summary of the early engineering predictions is presented in Fig. 5. Figure 5(a) shows the radiation equilibrium temperature time histories for the nosecap and the leading edges of the strake and wing. As noted previously, the nosecap and wing leading edge are constructed of SIRCA tile. An emissivity of 0.86 is therefore assumed for these areas. Comparison with similar calculations ${ }^{35}$ performed by ARC show reasonable agreement. Radia-

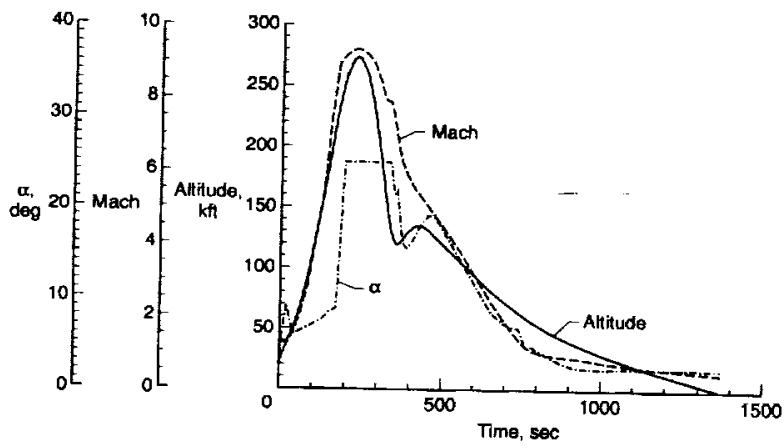

Fig. 4 WAGI8D trajectory profile. tion equilibrium temperatures shown throughout this paper are presented only as a general indicator of the thermal environment and do not account for the thermal mass of the system. Radiation equilibrium temperatures represent the maximum expected surface temperature values. Figure 5(b) shows the peak radiation equilibrium temperature and the total-heat-load distribution predicted for the windward centerline. A constant emissivity of 0.8 is assumed. The emissivity of the PCC coating used on the blankets varies from about 0.75 to 0.85 over this tem-

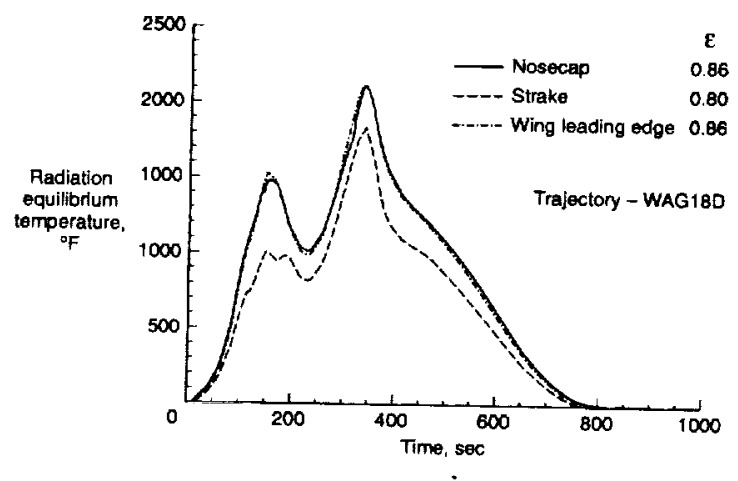

\section{a) Stagnation area temperature-time histories.}

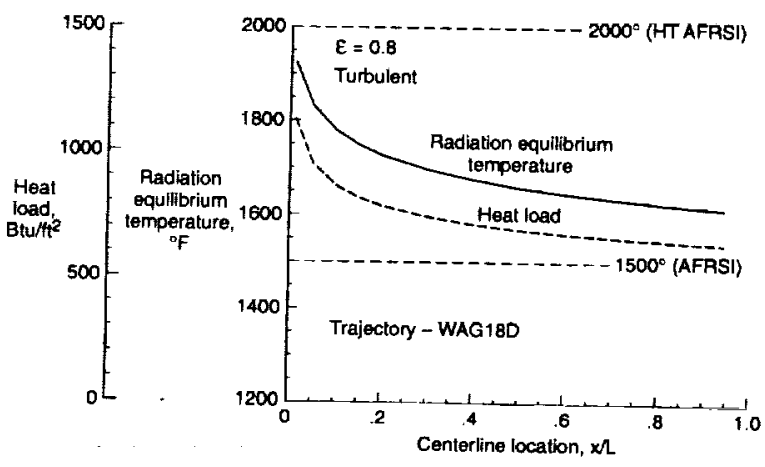

b) Windward centerline peak-heating distribution.

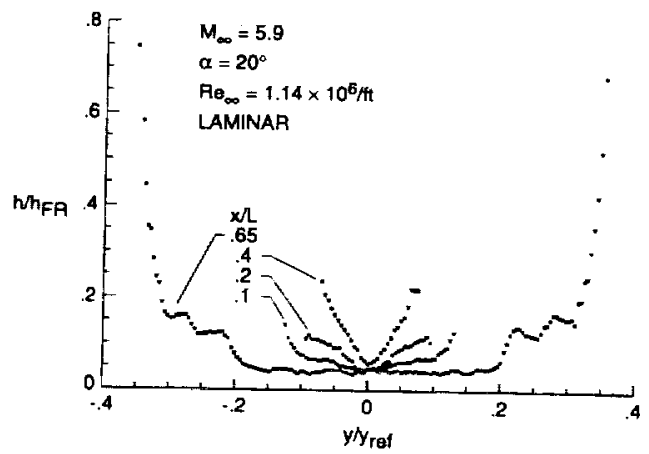

c) Experimental heating distributions.

Fig. 5 Preliminary aerothermal predictions. 
perature range. It can be seen that, even for this severe trajectory case, the centerline heating environments should be well within the capability of the HT-AFRSI. However, note that heating levels in the region where the flow expands around the chine of the vehicle would be expected to exceed the centerline values considerably.

The actual environments provided to the blanket designers, Oceaneering Space Systems (OSS), were presented in terms of the heat transfer coefficient and recovery enthalpy time histories for several points along the centerline. OSS coupled these environments with a thermal model based on the TPS material properties and design to generate the actual thermal loads and determine the required the blanket thicknesses. ${ }^{3}$ Figure $5(\mathrm{c})$ illustrates typical spanwise heating distributions at several $x \mathcal{L}$ stations (where $x$ is measured longitudinally from the tip of the nose, and $\mathrm{L}$ is the vehicle reference length) on the windward surface. These data were also provided to aid OSS in blanket design. The laminar distributions, based on the 0.0153 -scale model ${ }^{32}$ of the X000912 (a pre-outermold-line freeze configuration), were available for use in the initial blanket sizing and give some indication of the amplification of the heating from the centerline to the vehicle chine. Experience indicates that, although the turbulent heating levels will be higher, the amplification from the centerline to the chine will be reduced in turbulent flow, ${ }^{36}$ partially due to the reduced effect of crossflow on turbulent heating levels. The 20-deg AOA case was selected because it generally showed the highest amplification from the centerline to the chine. OSS was able to couple the centerline time histories with the wind-tunnel amplification to make an initial determination of the blanket requirements over the windward surface. The initial blanket sizing and layout by $\operatorname{OSS}^{3}$ was based entirely on these initial heating estimates and preliminary wind-tunnel heating distributions because no detailed computational solutions would be available until the outer mold line was frozen and surface and volume grids could be generated.

As additional wind-tunnel data became available it was used to confirm or suggest modification of the present engineering methodology. A sample of these data from Ref. 32 is presented in Fig. 6. Oil-flow views, similar to that presented in Fig. 6(a), showed evidence of inflow at AOA of $20 \mathrm{deg}$ and lower. This result suggested the use of a modification of Baranowski's crossflow method ${ }^{9}$ to account for the thickening of the boundary layer along the centerline due to inflow. This procedure has been shown to provide fairly good agreement with more detailed methods on vehicles such as the $\mathrm{X}-33^{20}$ which also experiences inflow at the lower AOA. Schlieren views, such as that illustrated for a 15 deg AOA case in Fig 6(b), show a relatively strong conical shock, thus confirming the choice of sharp-cone en- tropy for the engineering analysis. Figure 6(c) shows a typical windward centerline experimental heating distribution normalized by a reference Fay Riddell ${ }^{37}$ stagnation point value. These data show clear evidence of transition at about the $0.25 \mathrm{x} / \mathrm{L}$ station. The results of the MINIVER heating predictions are shown to be in good agreement with the laminar and turbulent experimental data. The thermal environments were updated to reflect the minor modification in methodology. The differences in maximum temperatures and total heat loads

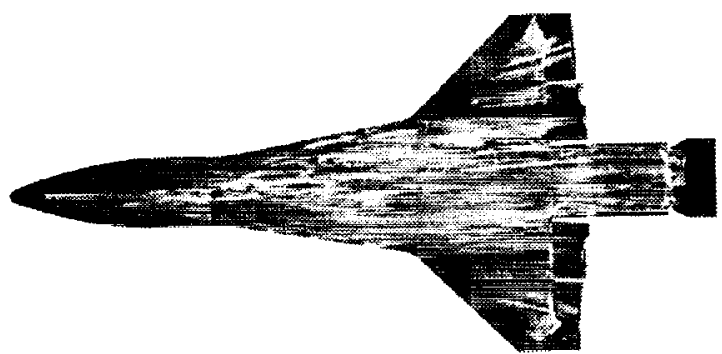

a) Oil-flow pattern (windside view, $\alpha=15^{\circ}$ ).

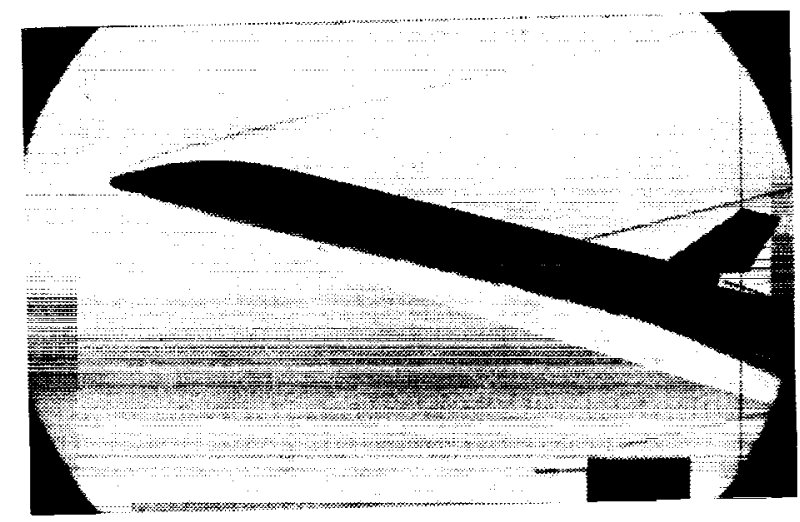

b) Schlieren image (side view, $\alpha=15^{\circ}$ ).

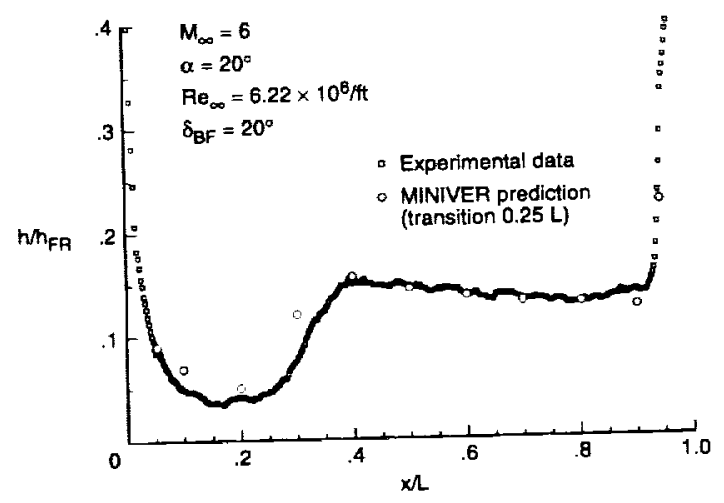

c) Comparison of MINIVER heat-transfer results with experimental data $\left(\alpha=20^{\circ}\right)$.

Fig. 6 Preliminary wind-tunnel results. 
were so insignificant that no modification of the blanket sizing was required. Although, wind-tunnel tests often cannot match the actual flight Reynolds number conditions or flow chemistry, comparisons such as that shown in Fig. 6(c) validate the analysis tools for application to actual flight conditions.

\section{Trajectory Considerations}

The rapid pace of the $X-34$ program required the environment predictions to be updated repeatedly as the vehicle configuration and trajectory were developed. All trajectories discussed herein have been generated by OSC. The initial trajectory (WAG18D), available in July of 1996 and shown in Fig. 4, was based on a 3-degreeof-freedom analysis (control deflections and trim requirements not necessarily considered) using the vehicle weight and performance available at that time. The maximum Mach number is about 9.3 and the maximum AOA is $25 \mathrm{deg}$. An updated trajectory profile, designated the DRM2, was made available at the Systems Requirements Review early in the fall of 1996 . This trajectory, illustrated in Fig 7(a), reached a Mach number of only about 7.4 with the same maximum AOA (25 deg), apparently indicating either reduced performance of the vehicle or a change in mission requirements. One feature which should be noted in each of these early trajectories is the "bounce" that occurs at about 110 to $120 \mathrm{kft}$. Once the outer mold line was "frozen" in December of 1996 , higher fidelity trajectories could be developed. As part of this effort, a guidance system would need to be designed. OSC elected to eliminate the "bounce" in the trajectory in order to reduce the demands on the guidance system. The two trajectories shown in Figs. 7(b) and $7(\mathrm{c})$ and are designated the X1004601 and the $X 1004701$ trajectories respectively. The altitude-time histories clearly show that the "bounce" has been successfully eliminated from both. Similar, to the DRM2, the X1004601 has a peak Mach number of 7.4 and a maximum AOA of $25 \mathrm{deg}$. The X1004701, on the other hand, has peak Mach number of 8.6 and maximum AOA of $30 \mathrm{deg}$. It would be expected that the latter trajectory would yield the more severe windward heating environment with a possible reduction on the leeward side due to the increased AOA. However, at the request of OSC, LaRC provided all thermal environments based upon the $\mathrm{X} 1004601 \mathrm{flight}$ conditions. Possible reasons for OSC's initial selection of this trajectory to be used for blanket design will be discussed later in this section.

Figure 8 illustrates a comparison of the four trajectories in terms of reference heating levels. Reference values are based on a Fay-Riddell ${ }^{37}$ calculation of the stagnation heating to a $\mathrm{l}-\mathrm{ft}$ sphere, corrected for a hot wall. These results indicate that the original trajectory
(WAG18D) would probably subject the vehicle to the highest temperatures, requiring more extensive use of the high temperature blankets, while the X1004701 would result in the greatest heat loads, possibly requiring greater TPS thicknesses. It should also be noted that the peak heating levels for all the newer trajectories are similar, and significantly lower than those for the initial design trajectory. Hot wall heating results presented in Fig. 9 show that the X1004701 trajectory presents somewhat more severe environments than the X1004601. A

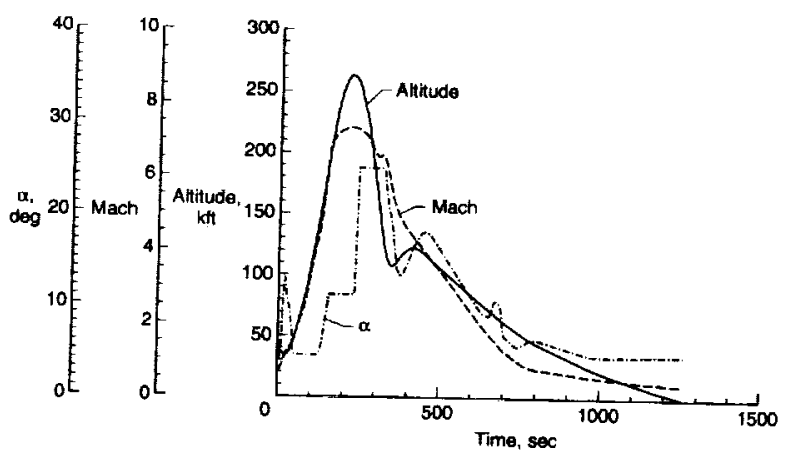

a) $D R M 2$.

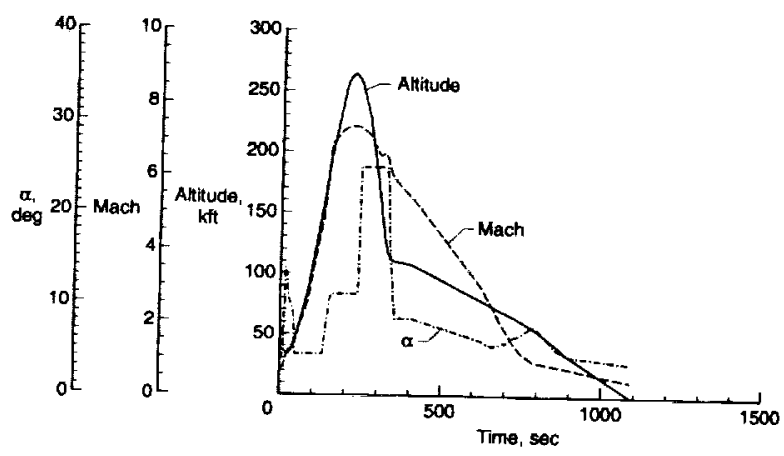

b) X100460I (TPS blanket design trajectory).

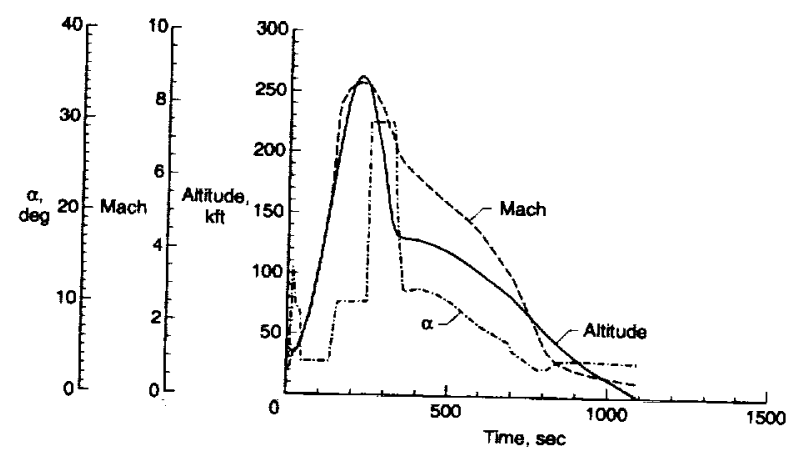

c) $X 1004701$.

Fig. 7 Trajectory profiles. 


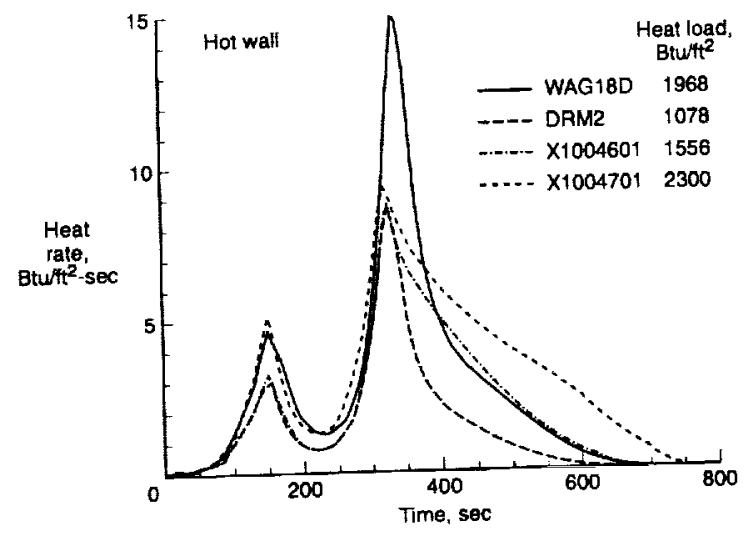

Fig. 8 Reference heating-rate comparisons for the design trajectories.

cold wall heating comparison, presented in Fig. 9(b) for the same trajectories, would suggest the opposite conclusion. Trajectory codes such as the Program to Optimize Simulated Trajectories (POST) ${ }^{38}$ typically use a cold-wall heating indicator and it is likely that such cold

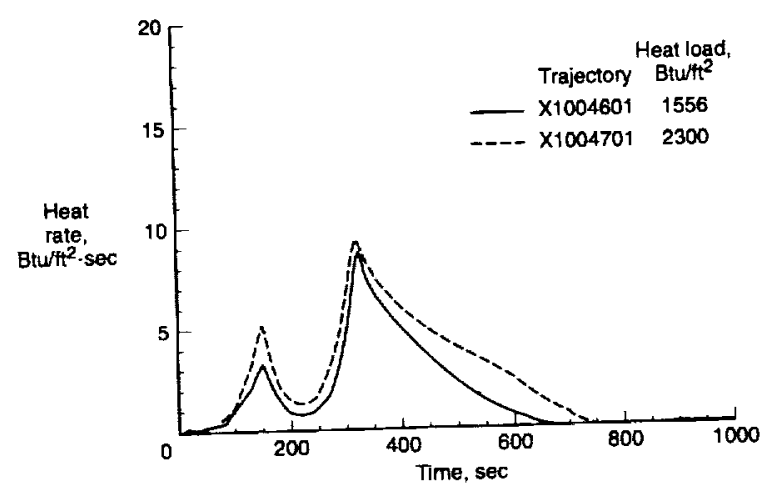

a) Hot-wall reference heating-rate time histories.

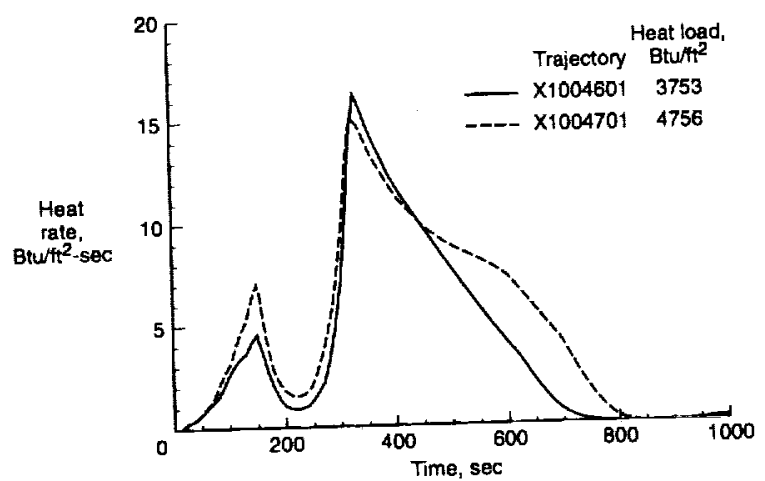

b) Cold-wall reference heating-rate time histories. wall results led to OSC's decision to design the blankets based on the X1004601 trajectory. For flight conditions similar to those for the X-34 where the ratio of the wall enthalpy to recovery enthalpy is fairly high $(\sim 0.4)$, care must be exercised if cold wall heating rates are to be used as a measure of heating levels during trajectory development.

Although the acreage areas are to be designed for fully turbulent flow, the trends seen in the reference heating levels will hold in these regions as well. This fact is evident in Figs. 9(c) and 9(d) which illustrate the peak temperature and heat-load distributions respectively along the windward centerline. The temperatures and the loads are generally greater for the X1004701 trajectory than for the X1004601.

\section{Case Selection for Benchmark Solution}

All flight conditions selected for detailed analysis were chosen along the X1004601 trajectory profile at the request of OSC. Computational resources limited the number trajectory points to a total of six. The trajectory

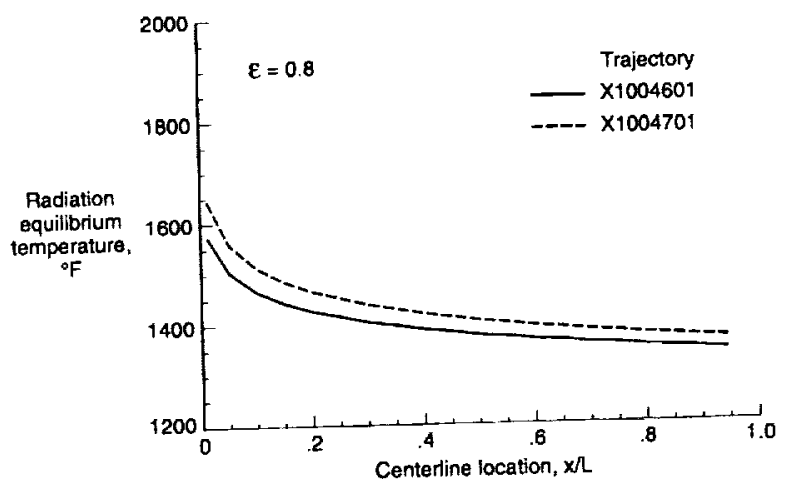

c) Windward-centerline peak-temperature distributions.

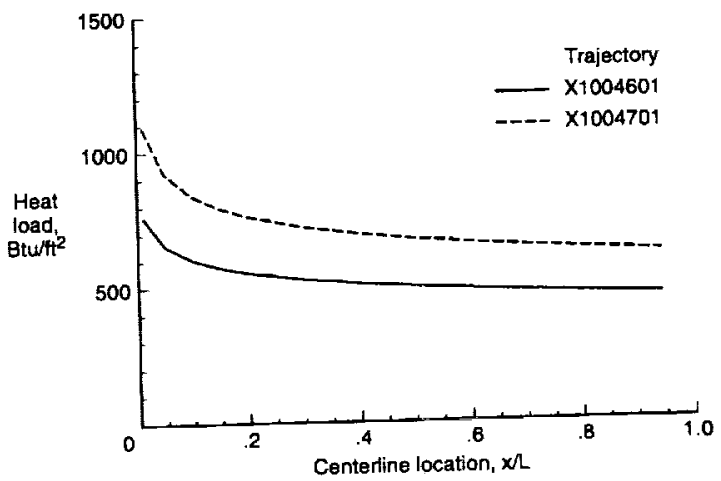

d) Windward-centerline peak-heat-load distributions.

Fig. 9 Heating comparison of the X1004601 and the X1004701 trajectories. 
points, the case numbers, and the associated parameters are listed in Table 1. Note, Case 2 was also calculated at the peak heating condition $(t=330 \mathrm{sec})$, but is not shown as it was not used to anchor the engineering results. LATCH solutions were available at all conditions,

Table 1 LATCH solutions

\begin{tabular}{|c|c|c|c|c|c|}
\hline $\begin{array}{l}\text { Time } \\
\text { (sec) }\end{array}$ & Case \# & $\begin{array}{l}\text { AOA } \\
\text { (deg) }\end{array}$ & $\begin{array}{c}\text { Mach } \\
\text { number }\end{array}$ & $\mathrm{Re} / \mathrm{ft}$ & $\begin{array}{c}\dot{\mathrm{q}}_{\mathrm{ref}}(\mathrm{hot}) \\
\left(\mathrm{Btu} / \mathrm{ft}^{2}-\mathrm{sec}\right)\end{array}$ \\
\hline 145 & 7 & 9 & 6 & $1.9 \times 10^{4}$ & 3.0 \\
\hline 152 & 4 & 11 & 6.83 & $1.4 \times 10^{4}$ & 3.1 \\
\hline 330 & $1 *$ & 23 & 6.32 & $2.8 \times 10^{5}$ & 8.3 \\
\hline 340 & $5^{*}$ & 15.22 & 6 & $3.6 \times 10^{5}$ & 7.3 \\
\hline 355 & 3 & 8 & 5.8 & $3.8 \times 10^{5}$ & 6.5 \\
\hline 578 & 6 & 6.48 & 3.6 & $7.5 \times 10^{5}$ & 0.9 \\
\hline 334 & $8 * *$ & 20.3 & 6.17 & $3.2 \times 10^{5}$ & 7.8 \\
\hline
\end{tabular}

* Viscous Solutions Available

** Additional LATCH solution obtained to check interpolation validity

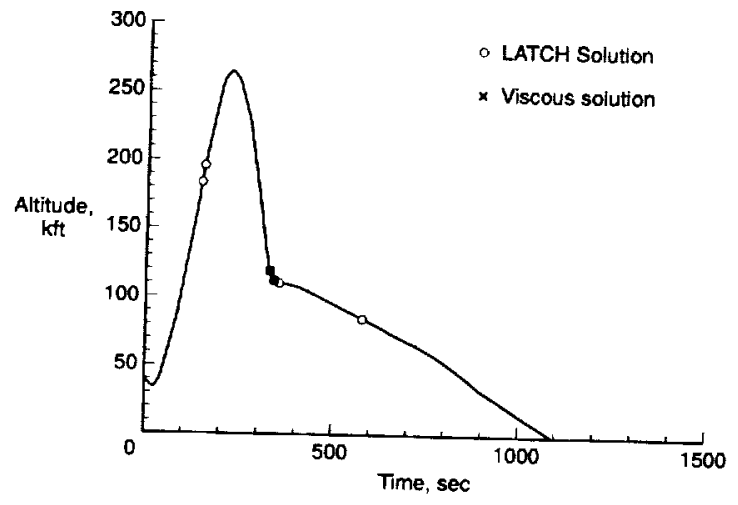

a) Altitude.

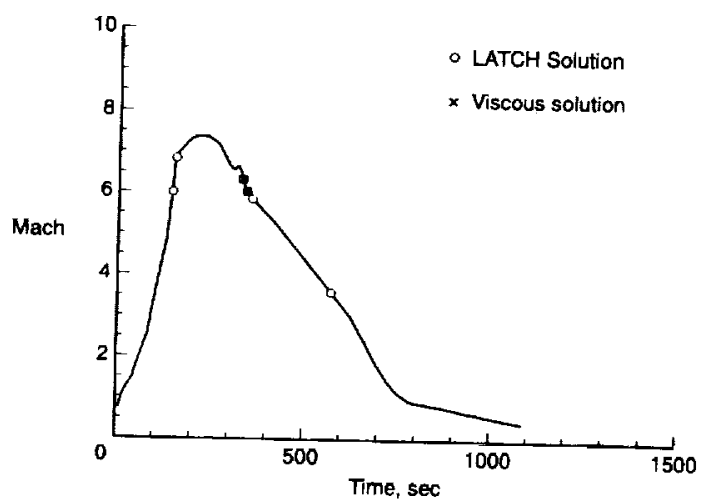

b) Mach number. whereas viscous solutions were only available for Cases 1 and 5. Case 8 will be discussed later in the paper and was not used in the initial analysis. Cases were chosen to include the peak heating on ascent and descent, as well critical AOA, and an appropriate range of Reynolds numbers. Figure 10 shows the critical trajectory parameters as functions of time. Included are; altitude-10(a),

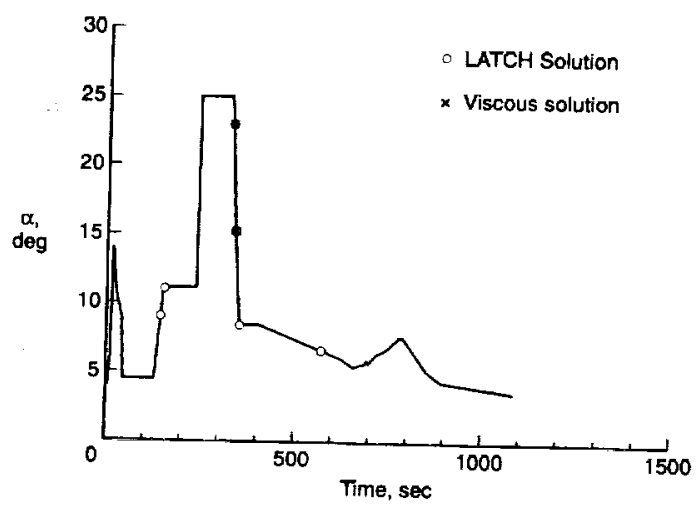

c) $\alpha$

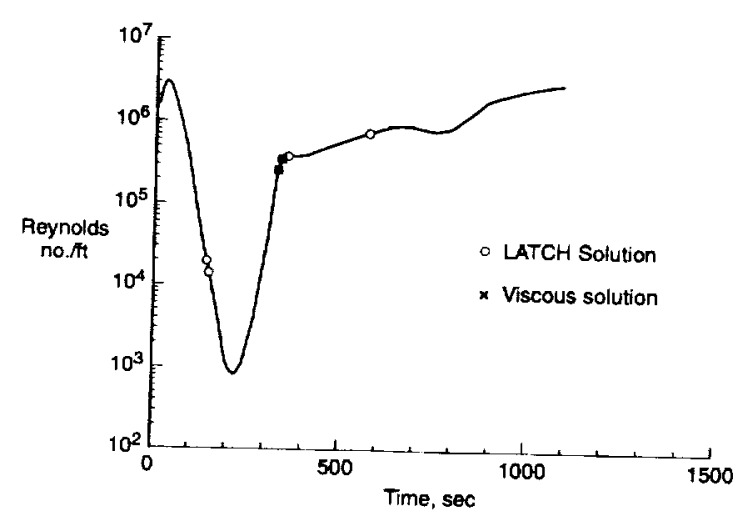

d) $R e_{\infty} / f t$.

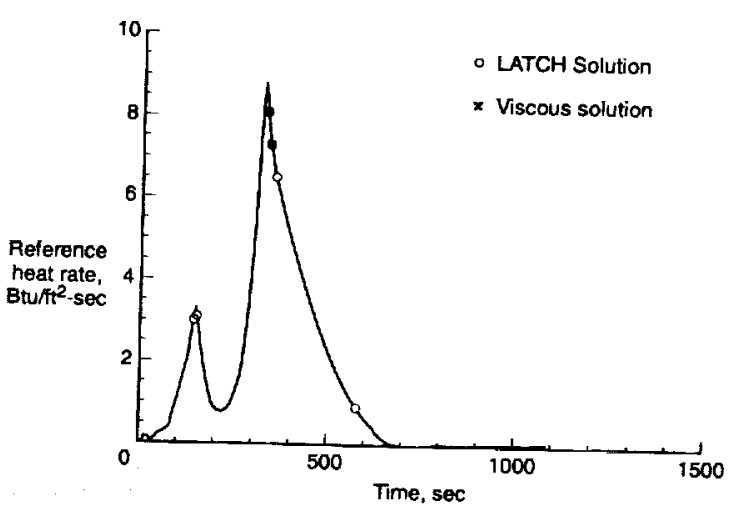

e) Hot-wall reference heating rate.

Fig. 10 X1004601 trajectory profile. 
Mach number-10(b), AOA-10(c), Reynolds number/ft$10(\mathrm{~d})$, and reference heating rate- $10(\mathrm{e})$. The $\mathrm{LATCH}$ (inviscid/boundary layer) solutions are identified on each plot, as are the points at which the viscous solutions were generated. Although the solutions appear to be "clumped" near peak heating, examination of the AOA profile indicates the reason for this choice. Accurate circumferential heat transfer distributions around the body are critical to the success of the methodology employed in this paper. Because the majority of the high-heating portion of the trajectory does not vary widely in Mach number and the flow state is defined to be turbulent, the chief influence on the heat transfer distributions is the AOA. As shown in Fig. 10(c), the AOA range is captured fairly well over the high heating portion of the entry (see Fig. 10(e)). The point at $330 \mathrm{sec}(23 \mathrm{deg})$ should adequately represent the peak heating to the windward surface while that at $355 \mathrm{sec}(8 \mathrm{deg})$ should represent the highest heating on the leeward surface due to the low AOA. The case at $340 \mathrm{sec}(15 \mathrm{deg})$ provides heating distribution definition where the AOA is changing rapidly. It is noted that the actual peak heating condition is not calculated as the result of the apparent selection of the peak heating point based on the cold wall values. Comparing Figs. 9(a) and 9(b) it is apparent that the peak in hot wall heating occurs prior to that for the cold wall, and therefore the points chosen fall on the downward slope of the reference heating profile. The lack of a solution exactly at peak heating should not impact the timedependent heating significantly, as the engineering solutions are run at the actual flight conditions with the heating distributions about the body based on the LATCH solutions. The difference in distributions at $25 \mathrm{deg}$ AOA compared to $23 \mathrm{deg}$ is expected to be small.

\section{Detailed Aerothermal Predictions}

\section{Code Validation}

Comparisons are presented in this section to demonstrate the validity of the more detailed techniques, as well as to further demonstrate the applicability of the MINIVER code. For the comparisons with the groundtest experimental heating data, several figures are used for the sake of clarity. Initially, the data are compared to the MINIVER predictions. Then the MINIVER results are compared to the LAURA and to the LATCH results respectively. Finally, comparisons of the predicted results are made at a flight-test condition.

The aerothermal environments used for the initial design of the blanket TPS were based strictly on engineering estimates coupled with preliminary wind-tunnel distributions. As the study progressed and the vehicle geometry was defined, wind-tunnel test data, LATCH solutions, and viscous solutions became available for

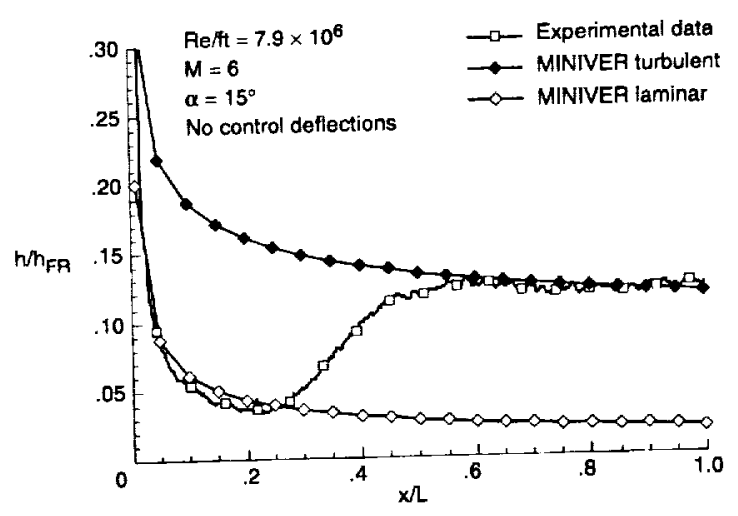

a) Experimental data (thermographic phosphor).

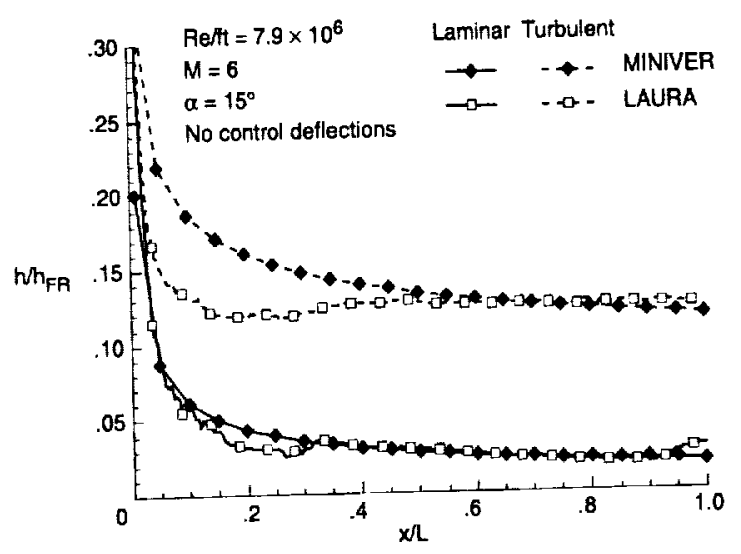

b) LAURA viscous results.

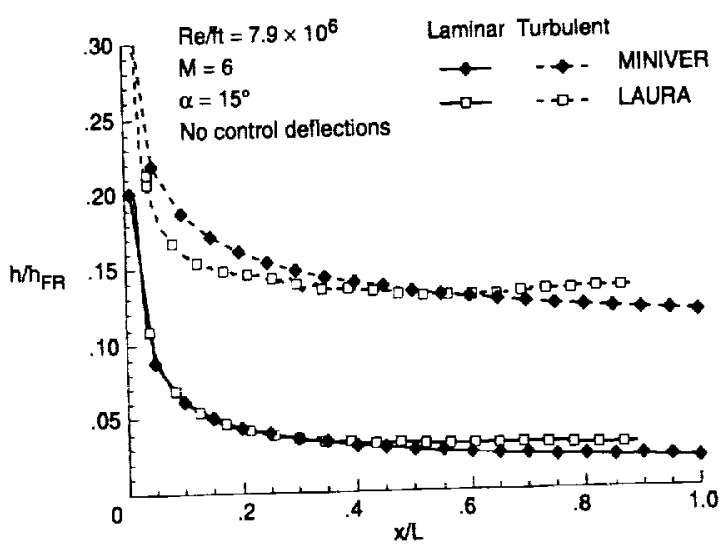

c) LATCH results

Fig. II MINIVER results compared at wind-tunnel test conditions. 
comparison to the engineering predictions. All engineering predictions shown here are made using the updated methodology as described in the Preliminary Aerothermal Predictions section. In Fig. 11 the MINIVER engineering predictions for the windward centerline of a 0.183 scale model of the X-34 configuration X0001215 at a wind-tunnel condition of Mach 6, an AOA of $15 \mathrm{deg}$, and unit Reynolds number of 7.9 million are compared to thermographic phosphor data ${ }^{32}$ and analytical predictions. ${ }^{19,25}$ In Fig. 11(a) the MINIVER predictions are compared with the thermographic phosphor data where transition is evident at an $\mathrm{x} / \mathrm{L}$ of $\sim 0.25$. Both laminar and turbulent MINIVER solutions are shown. Once again the data are presented in the form of $\mathrm{h} / \mathrm{h}_{\mathrm{FR}}$ (where $\mathrm{h}$ is the local heat transfer coefficient and $h_{F_{R}}$ is the Fay-Riddell reference value). Good agreement with the data is evident for both the laminar and turbulent results. MINIVER's overprediction of the laminar results in the forward portion of the body is expected and results primarily from the use of sharp-cone entropy conditions in this region where the streamlines are more likely to have passed through a higher angle shock near the nose of the vehicle. In Fig. 11(b) the MINIVER calculations are compared with the LAURA solutions. Once again good agreement is noted, particularly downstream where sharp cone entropy is most appropriate. Finally, in Fig 11(c), the MINIVER predictions are compared with those from the inviscid-boundary layer solution of LATCH. Reasonable agreement is demonstrated once again, although it is apparent by comparison with Fig. 11(a) that the LATCH solutions tend to over-predict the data and the viscous solutions at centerline stations downstream of approximately $0.6 \mathrm{x} / \mathrm{L}$. The difference appears, however, to be less than $10 \%$ for the turbulent data which is of primary interest here.

Figure 12 presents the MINIVER engineering prediction of turbulent heating rates along the windward centerline for the full scale vehicle at the peak-heating flight condition $(t=330 \mathrm{sec})$ on the X1004601 trajectory. Downstream of the $200 \mathrm{in}$. station where the sharpcone-entropy assumption is more appropriate, good agreement is shown with the viscous LAURA solution and the LATCH results computed for the same condition. Similar levels of agreement are shown for the radiation equilibrium temperatures not shown here.

A MINIVER generated temperature-time history is shown in Fig. 13 for a representative location on the windward centerline for the X1004601 trajectory (used for blanket design). The LATCH-generated values are shown for comparison. It is evident, that, even without adjustment, the MINIVER predictions of the temperatures is in excellent agreement with the LATCH predictions. Where any noticeable difference exists MINIVER tends to overpredict, resulting in the conservative esti-

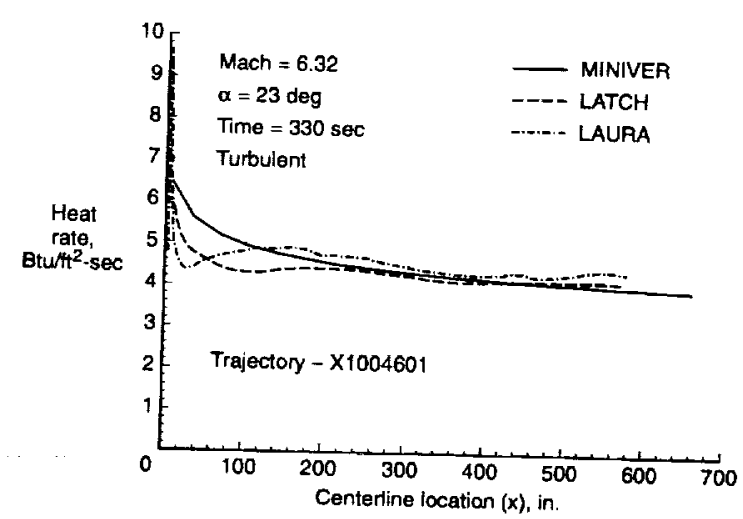

Fig. I2 MINIVER/LAURA/LATCH predictions compared at flight condition (Case I).

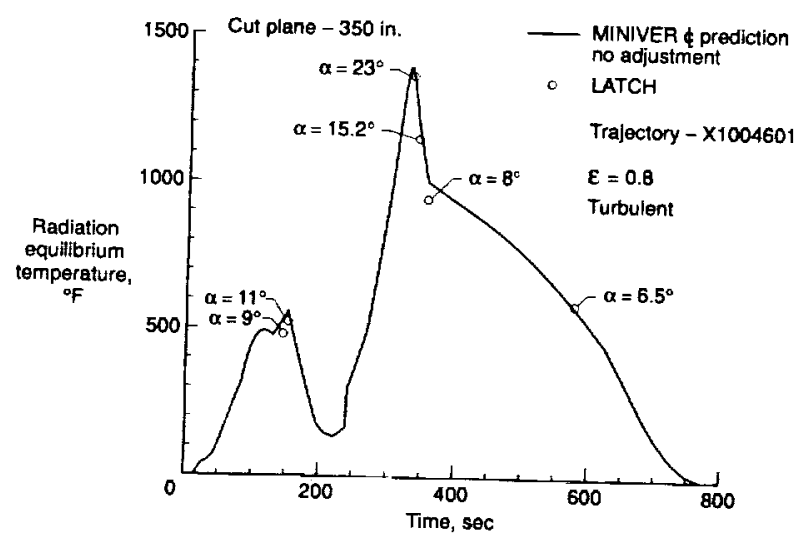

Fig. 13 MINIVER temperature comparison with LATCH results.

mate desired. It should be noted that, particularly in regions of steep temperature gradients, a certain degree of error is introduced because the LATCH solutions are allowed to come to equilibrium at a constant wall temperature whereas the MINIVER wall temperature lags the radiation equilibrium value slightly. This case is typical of the agreement shown along the windward centerline for stations downstream of the nose region.

Comparisons of the MINIVER predictions with wind-tunnel data and detailed solutions at flight conditions suggest that the initial heating predictions provided for blanket design will be somewhat conservative over the forward portion of the vehicle, but predict the environments over the remainder of the acreage with reasonable accuracy. This, in combination with the more severe trajectory originally considered, indicates that the blanket TPS designed using the original environments provided and the WAG18D trajectory should be sufficient to handle both the maximum temperatures and total heat loads associated with the refined trajectories now available. Demonstration of the validity of the engineer- 
ing predictions is critical to early definition of accurate thermal environments. However, once a sufficient number of detailed solutions become available, the accuracy of the enginecring predictions is less important as they are anchored to the detailed solutions and the engineering methods are then used primarily as an interpolation tool for the trajectory conditions which fall between those for which detailed solutions are available.

\section{Methodology}

Limited computational resources together with the time constraints imposed by the program schedule precluded the generation either of sufficient number of LAURA viscous solutions or a sufficient number of LATCH solutions to provide the time-dependent thermal environments necessary for TPS design. Instead, two LAURA solutions ${ }^{25}$ were generated at or near peak heating for the appropriate AOA and flight conditions. LATCH solutions were computed for the same cases and at four additional flight conditions. The LATCH solutions are shown to compare well with the corresponding viscous cases in Ref. 19. The six LATCH cases were then used to anchor the engineering solutions. Finally, the MINIVER solutions, thus anchored to the LATCH solutions, were used to interpolate in time, Mach, Reynolds number, and AOA to provide the required heating time histories at eighty points on the body. A description of the way in which this process was implemented follows.

Centerline Adjustments: Figure 14 shows a typical comparison of MINIVER and LATCH heat-transfer coefficients for the windward centerline. This particular figure shows the heating comparison at $330 \mathrm{sec}$ on the $\mathrm{X} 1004601$ trajectory. Plots such as this are used to determine the factors necessary to correct the MINIVER prediction to match the LATCH value. The ratio of $h_{C L}$ (the LATCH value) to $h_{\text {min }}$ (the MINIVER prediction) is determined for approximately twenty locations along the windward centerline from a point immediately aft of the nosecap, $\sim 15$ in., to the end of the LATCH solutions at approximately $560 \mathrm{in}$., including the point identified at an axial station of $350 \mathrm{in}$. This procedure is repeated for each condition for which a LATCH solution is available, a total of six in this case.

Off-Centerline Adjustments: Once the adjustment factors have been determined for the centerline, an additional correction must be determined to adjust the predictions to match the heating distributions at locations away from the centerline. Figure 15 presents typical circumferential heating distributions for three different times along the X1004601 design trajectory representing AOA of 8.0, 15.2, and $23 \mathrm{deg}$. The data are pre-

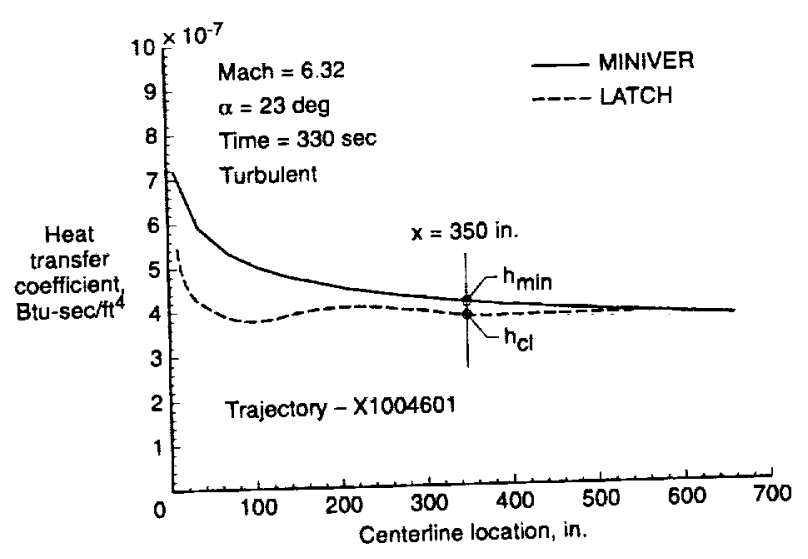

Fig. 14 MINIVER/LATCH windward-centerline heattransfer coefficient comparison for peak heating case

(Case I).

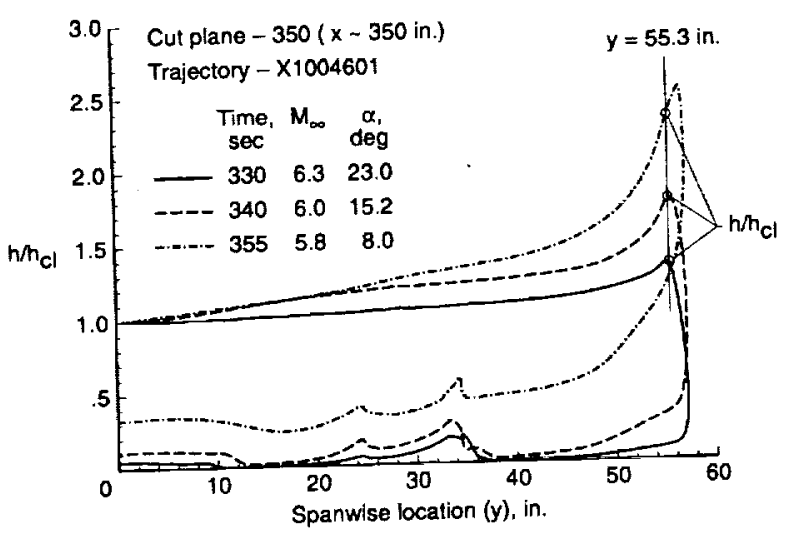

\section{Fig. 15 Typical turbulent circumferential heating distributions from LATCH.}

sented as an $\mathrm{h} / \mathrm{h}_{\mathrm{CC}}$ distribution for a cut plane ${ }^{19}$ located at an axial station of $350 \mathrm{in}$., corresponding to the centerline location identified in the previous figure. The increasing influence of inflow with reduced AOA is evidenced by the corresponding increase in heating amplification at the most outboard locations. (see Ref. 19 for other sample heating distributions and comparisons with the viscous results) For each solution and each cut plane, factors were evaluated at a sufficient number of spanwise locations to adequately define the distribution (typically three to five points) such that linear interpolation between points would yield reasonable agreement with the detailed solution. A point representing the greatest amplification factor at the peak heating condition, $330 \mathrm{sec}$, was always chosen as one of the points in order to ensure that the peak temperature at or near the leading edge would be captured for the blanket TPS design. Once the $\mathrm{h} / \mathrm{h}_{\mathrm{C}}$ factors have been determined for each point and each solution, these were multiplied by the original 
centerline factor $\left(h_{\mathrm{cl}} / \mathrm{h}_{\text {min }}\right)$ to determine the required MINIVER adjustment factor. The local heat transfer coefficient (h) is calculated using the following equation:

$$
\mathrm{h}=\mathrm{h}_{\min } \times\left(\mathrm{h}_{\mathrm{CL}} / \mathrm{h}_{\min }\right) \times\left(\mathrm{h} / \mathrm{h}_{\mathrm{CL}}\right)
$$

where: $h_{\mathrm{cL}} / h_{\min }$ is evaluated at the appropriate centerline location

$\mathrm{h} / \mathrm{h}_{\mathrm{CL}}$ is evaluated at the desired spanwise position along the cut plane

$h_{\text {min }}$ is calculated as a function of time using standard engineering techniques.

Thus a MINIVER-generated centerline heating-rate timehistory can be corrected to yield the time-dependent thermal environment for any point on the body for which the appropriate set of factors has been determined. The next session discusses the appropriate application of these factors given a limited number of detailed solutions so that a valid interpolation of the heat transfer can be performed.

Solution Application: Ideally a database which contains solutions for a range of AOA, Mach number, and Reynolds number would be created. However, available time and resources precluded that approach here and limited the data set to six solutions at conditions on the X1004601 trajectory (see Table 1). Engineering judgment was required to choose the appropriate application of this limited solution set over the trajectory. TPS sizing required computations be performed at small time increments over the entire time of the trajectory $(\sim 700$ seconds from release of the vehicle through ascent to $264 \mathrm{kft}$ and descent back to Mach 1.5). Referring to Fig. 10(e), it is apparent that the majority of the heating will occur between 100 and $600 \mathrm{sec}$ making the case selection before and after those times less critical. Wherever a solution was available it was applied. Table 2 lists the trajectory times at which the six solution cases were applied. Additionally, this table lists the corresponding range of $\mathrm{AOA}$,

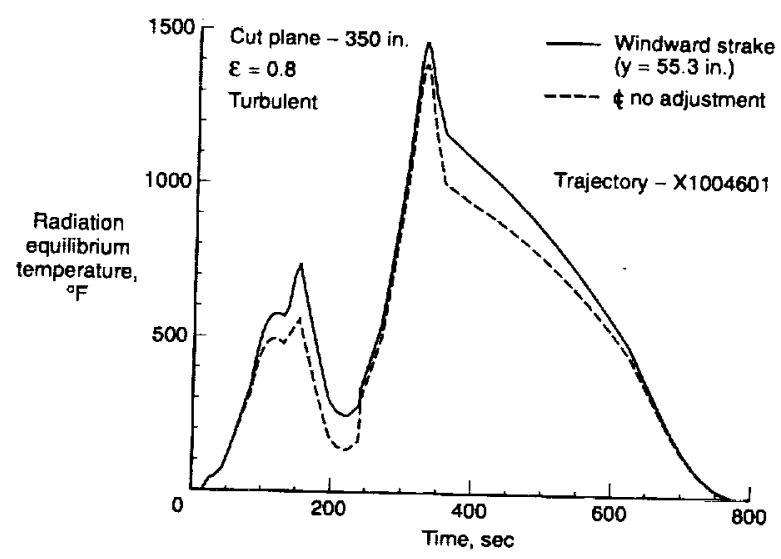

Fig. 16 Typical temperature-time history for centerline adjusted to windward strake location.

Mach, and Reynolds numbers. In the time from 100 to $600 \mathrm{sec}, \mathrm{AOA}$ was given priority in case selection. Comparison of the conditions in Table 2 with those in Table 1 for the design cases shows that Mach numbers generally did not vary significantly from the design point used. In some cases Reynolds number is seen to vary substantially from the design case. However, because a fully turbulent boundary layer was assumed for all heating distributions this variation was not considered critical. Where two times are listed, the distributions were held constant (but not the MINIVER reference). Times were generally chosen such that the flight AOA corresponded to those of the detailed solutions, thus allowing linear interpolation from one time step to the next. Figure 16 shows a typical radiation equilibrium temperature profile resulting from this process. The dashed line represents the MINIVER centerline time history without adjustment, while the solid line represents the heating associated with an outboard point at the corresponding cut plane. This particular location represents a windward point near the edge of the strake. The points on the body at which detailed time histories were provided for blanket design will be discussed in a later section.

Table 2 Trajectory application of LATCH solutions for interpolation

\begin{tabular}{cccccc}
\hline $\begin{array}{c}\text { Time } \\
(\mathrm{sec})\end{array}$ & Case \# & $\begin{array}{c}\text { AOA } \\
(\mathrm{deg})\end{array}$ & $\begin{array}{c}\text { Mach } \\
\text { number }\end{array}$ & Re/ft & $\begin{array}{c}\dot{\mathrm{q}}_{\text {ref }} \text { range (hot) } \\
\left(\mathrm{Btu} / \mathrm{ft}^{2}-\mathrm{sec}\right)\end{array}$ \\
\hline $0-137$ & 6 & $4-14$ & $.7-5.2$ & $3.0 \times 10^{4}-1.5 \times 10^{6}$ & $.1-2.5$ \\
145 & 7 & 9 & 6 & $1.9 \times 10^{4}$ & 3.0 \\
$150-240$ & 4 & $10.5-11.1$ & $6.7-7.3$ & $1.1 \times 10^{3}-1.5 \times 10^{4}$ & $.9-3.2$ \\
$242-331$ & 1 & $23-25$ & $6.3-7.3$ & $1.1 \times 10^{3}-2.8 \times 10^{5}$ & $.9-8.3$ \\
340 & 5 & 15.22 & 6 & $3.6 \times 10^{5}$ & 7.3 \\
355 & 3 & 8 & 5.8 & $3.8 \times 10^{5}$ & 6.5 \\
$578-714$ & 6 & $6.6-5.5$ & $1.6-3.5$ & $7.7 \times 10^{5}-8.5 \times 10^{5}$ & $0-.9$ \\
\hline
\end{tabular}




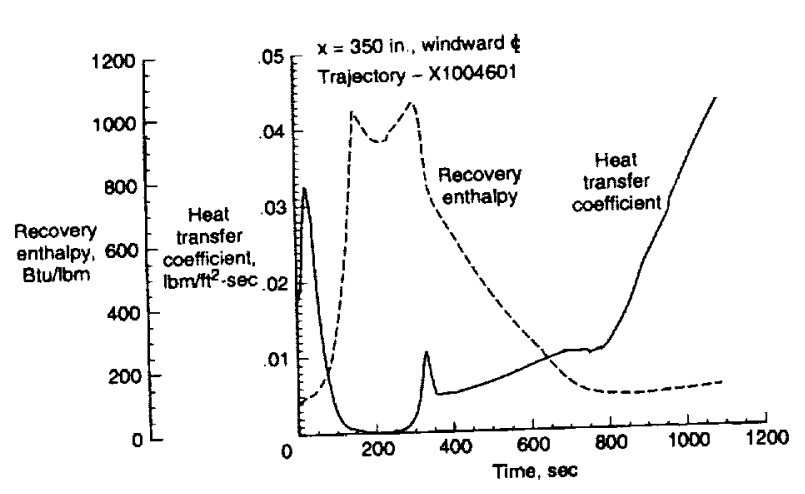

Fig. 17 Typical heat-transfer-coefficient and recoveryenthalpy time histories for blanket design.

Aerothermal Environments: The aerothermal environments for blanket design were provided in the form of time-dependent heat-transfer coefficients and recovery enthalpies (adiabatic wall enthalpies) similar to those illustrated in Fig. 17 for a typical centerline location. The blanket designers were then able to perform a thermal balance, coupling the applied environments provided with the material response of the TPS, to determine the blanket thickness necessary to ensure that structural temperatures limits would not be exceeded. ${ }^{3}$ The detailed solutions $^{19,25}$ were used to determine the distribution of the different blanket materials (HT-AFRSI, AFRSI, and FRSI) depending upon the maximum surface temperatures anticipated.

As noted previously, radiation equilibrium temperatures are presented here only as a general indicator of the thermal environment and do not account for the thermal mass of the system. In the following Results section of the paper, several radiation-equilibrium time histories will be presented. The locations for the calculations include the wind and lee surfaces as well as the side of the vehicle. The results are presented to give a general understanding of the temperature environments for the $\mathrm{X}-34$ blanket design trajectory (X1004601).

\section{Results}

\section{Analysis Locations}

Figure 18 shows the locations (standard body-oriented $x, y, z$ coordinate system with the $x$-axis origin at the nose, the $y$ axis oriented out the starboard wing, and $z$ defined by the right-hand rule) selected for calculation of the time-dependent aerothermal environments. The locations are superimposed on windward, leeward, and side views of the X-34 vehicle. LATCH results ${ }^{19}$ are indicated in terms of temperature contours. Fifty windside locations were chosen based on the peak-heating case, Case $1(\mathrm{Mach}=6.32, \mathrm{AOA}=23 \mathrm{deg}$, time $=330 \mathrm{sec})$ and are shown in Fig. 18(a). They include locations on

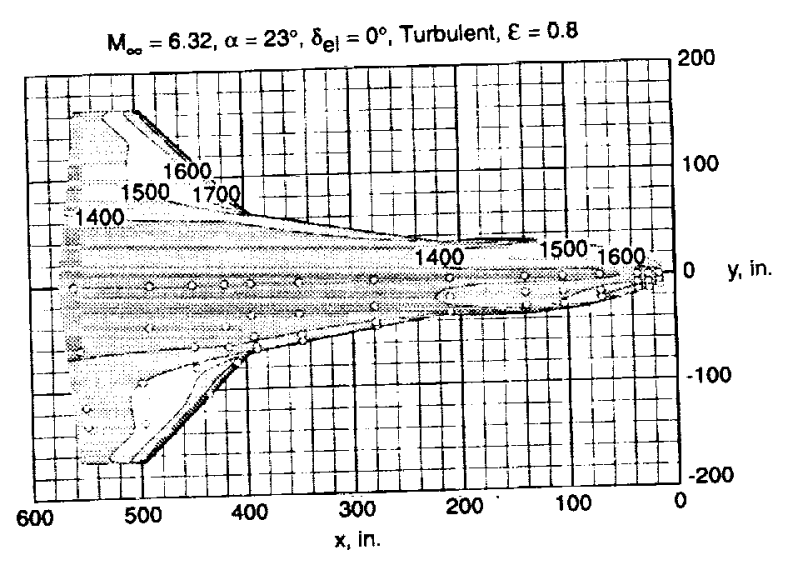

a) Windside view (Case l).

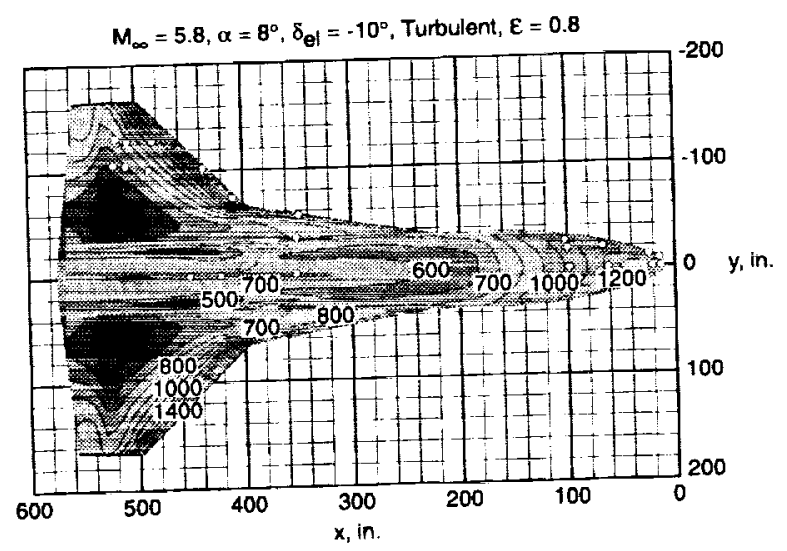

b) Leeside view (Case 3).

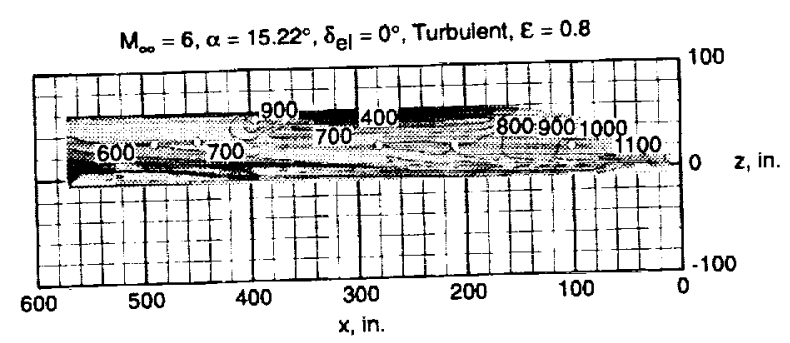

c) Side view (Case 5).

fourteen cut planes. Points along the cut planes were selected such that linear interpolation between the points would generally yield a fair representation of the results. Two additional points on the centerline of the undeflected bodyflap were calculated ( $x=630 \mathrm{in}$. and $x=660 \mathrm{in}$.), but not shown because the LATCH solution did not extend to that region. 
Comparison of all the $\mathrm{LATCH}$ solutions confirmed that Case $3(\mathrm{Mach}=5.8, \mathrm{AOA}=8 \mathrm{deg}$, time $=355 \mathrm{sec})$ represented the worst-case heating on the leeward surface, primarily due to the low AOA at relatively high reference-heating levels. Shown in Fig. 18(b), superimposed on the LATCH results for Case 3, are the locations of the twenty-two leeward points for which timehistories were provided. These included eight points on the wing, two on the strake and the remainder on the fuselage. No points were provided for the deflected elevons, apparent in the Fig. 18(b) at roughly the $530 \mathrm{in.}$ station.

Time-dependent environments at additional locations on the side of the fuselage were also provided. These locations are marked on Fig. 18(c) which also shows the LATCH temperature contours for Case 5 $(\mathrm{Mach}=6, \mathrm{AOA}=15.22 \mathrm{deg}$, time $=340 \mathrm{sec})$. Of the seven side-fuselage locations calculated, an important one to note is that at the $x$ location of roughly $400 \mathrm{in}$. and the $z$ location of roughly $50 \mathrm{in}$. This represents the

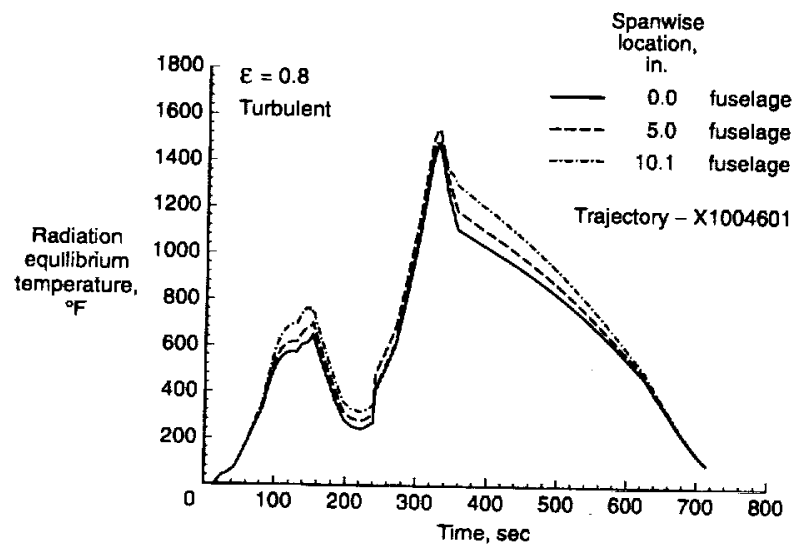

a) Cut plane- $15 \mathrm{in.}$

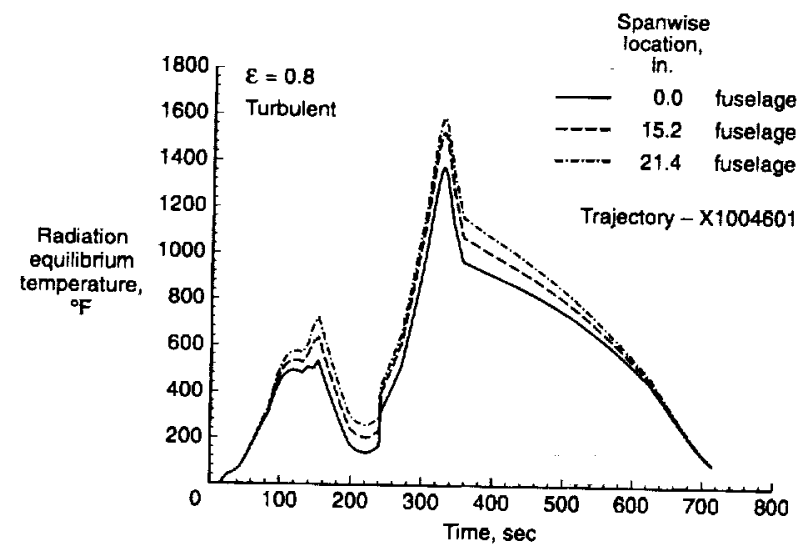

b) Cut plane - $70 \mathrm{in}$. peak heating on this surface, and occurs at the juncture where the rounded forward fuselage transitions to the square cross-section.

\section{Windward Surface Heating}

Windside time-dependent aerothermal environments have been calculated for a total of fifty-two points. Typical results, presented in the form of radiation equilibrium time histories, are shown in Fig. 19. Figures 19(a-d) represent calculations at four representative cut planes; $x=15,70,350$, and 450 in. As can be seen in Fig. 18(a), the forward two cut planes lie entirely on the fuselage, while the latter two include points on the strake and wing respectively. The trends in the time histories are generally consistent, the outboard locations tracking the centerline results, but with some amplification in heating. This amplification is particularly evident on the 450 in cut plane near the leading edge of the wing (Fig. 19(d)). Assuming the radiation equilibrium temperatures provide a reasonable representation of the surface heating

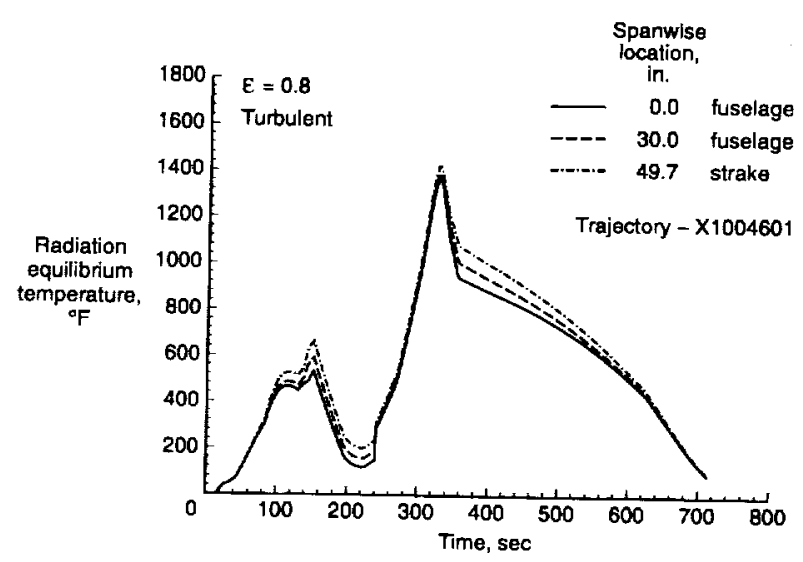

c) Cut plane - $350 \mathrm{in}$.

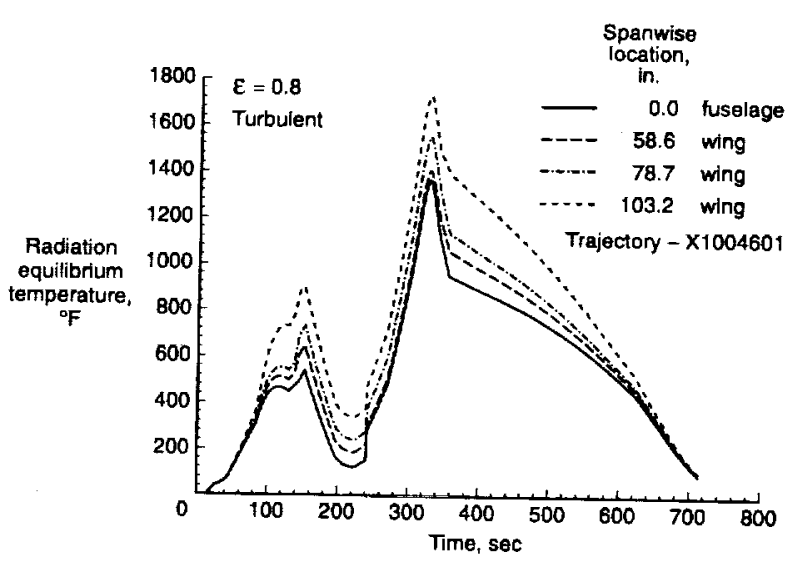

d) Cut plane-450 in.

Fig. 19 Typical windside temperature-time histories. 
levels, the temperature capability of the HT-AFRSI selected for use over this region (see Fig. 3) does not appear to be exceeded for any of the points calculated.

\section{Leeward Surface Heating}

Time-dependent aerothermal environments have been calculated for a total of twenty-two points on the leeside of the vehicle. Figure 20 illustrates typical timedependent results for this surface at four cut planes; $x=15,70,350$, and 450 in. Once again, the forward two cut planes lie entirely on the fuselage, while the latter two include points on the strake and wing respectively. As expected, maximum temperatures are shown to be significantly lower on the lee surface than those seen previously on the windward surface (see Fig 19). Peak heating on the leeward surfaces appears to be delayed slightly from that evident on the windward surface. Unlike the windward surface, heating on the leeside lags the peak reference heating slightly and occurs as the AOA drops rapidly and the leeside starts to see more flow. The character of the heating on the leeward surface also differs from that on the windward surface in

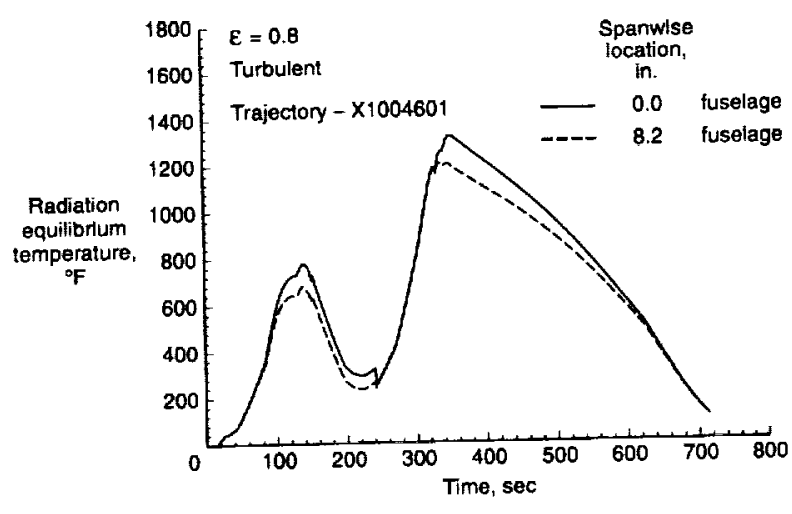

a) Cut plane-15 in.

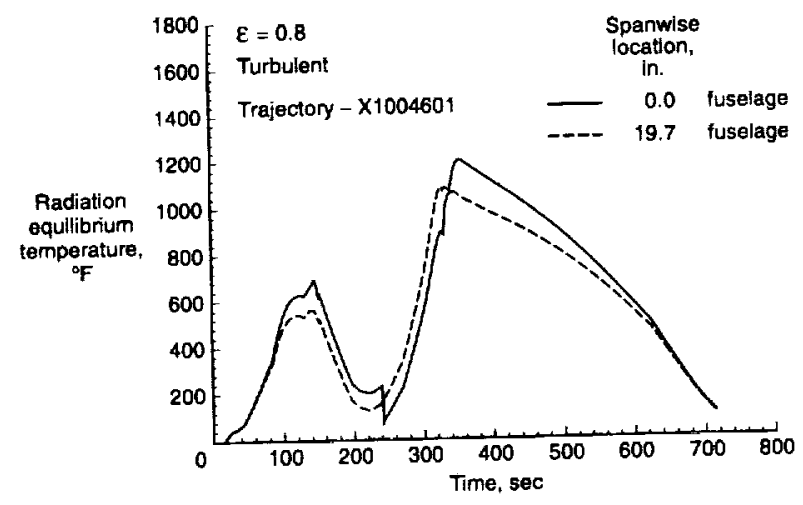

b) Cut plane- $70 \mathrm{in}$. that the heating, although not as high in magnitude, remains at higher levels for a longer period of time as the vehicle AOA is decreased (i.e. the heating does not drop off as rapidly after peak heating). As can be seen by comparing the blanket layout in Fig. 3 with the analysis locations shown in Fig. 18b, all these locations (with the exception of the point on the 450-in. cut plane near the leading edge of the wing (SIRCA) and the centerline locations on the 350- and the 450-in. cut planes (FRSI)) are protected with the standard AFRSI which has a maximum use temperature of $1500^{\circ} \mathrm{F}$. Examining the time histories in Fig. 20, it appears that this temperature is unlikely to be exceeded for any of these locations. Even the point near the leading edge of the wing on the 450in. cut plane exceeds $1500^{\circ} \mathrm{F}$ only slightly (see Fig. 20(d)). The SIRCA tile at the leading edge should be sufficient to handle this thermal environment.

The majority of the lee surface of the wing is to be protected by FRSI as is the aft portion of the leeward fuselage. Figure 21 illustrates the radiation equilibrium time histories for two points on the leeward surface of the wing. Both points appear to exceed the FRSI capa-

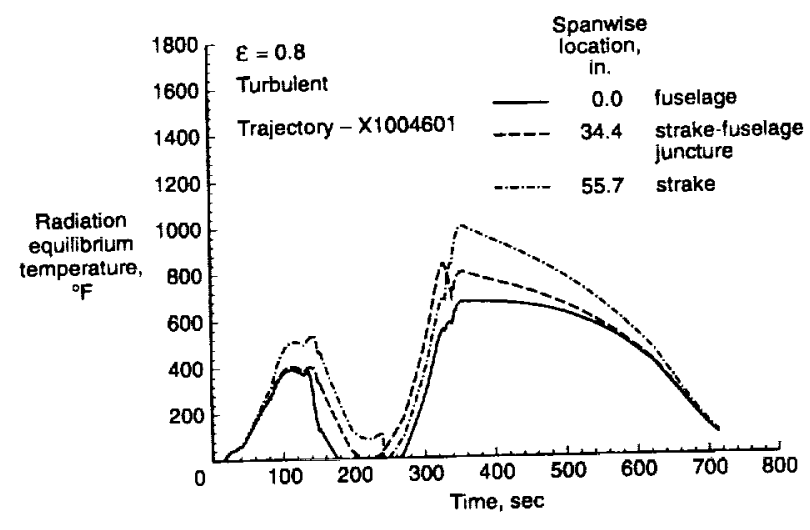

c) Cut plane- 350 in.

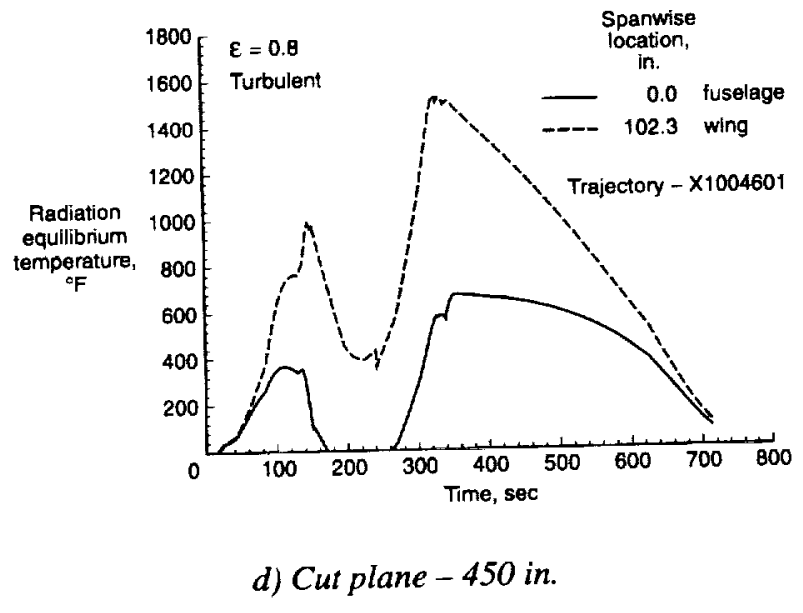

Fig. 20 Typical leeside temperature-time histories. 


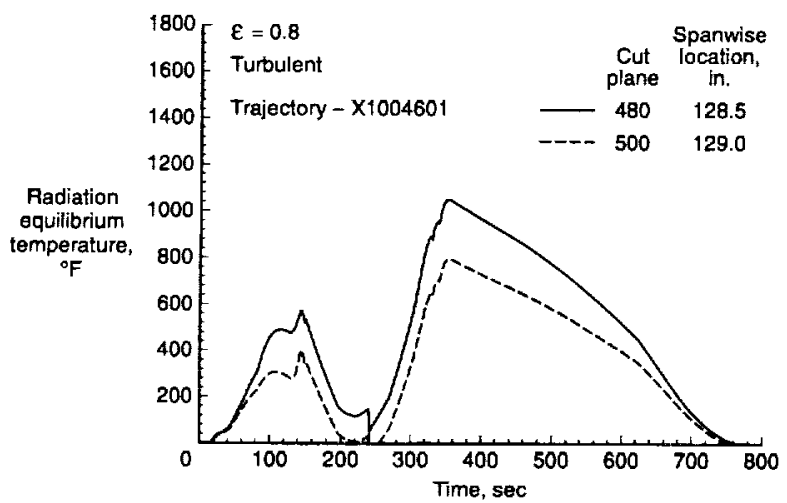

Fig. 21 Typical leeward wing temperature-time histories.

bility of $700^{\circ} \mathrm{F}$. However, the blanket layout in Fig. 3 is not sufficiently detailed to determine whether these points (shown in Fig. 18(b)) would actually lie within the FRSI area. The centerline locations on the 350- and the 450-in cut plane (mentioned previously) do appear to lie within in the region protected by FRSI. The predictions shown in Figs. 20(c) and 20(d) respectively for these points show maximum temperatures just within the FRSI capability.

\section{Side Surface Heating}

Time-dependent aerothermal environments have also been calculated for seven side surface locations, including a point at the 395 -in cut plane where the body cross-section transitions from circular to rectangular. Figure 22 illustrates some typical results for the side fuselage. Except for the fuselage transition zone, the peak temperatures along the fuselage fall in the $750-850^{\circ} \mathrm{F}$ range. Comparing that result with the blanket distribution shown in Fig. 3, it is evident that the regions aft of 300 in. which are protected by FRSI are likely to exceed its temperature capability of $700^{\circ} \mathrm{F}$. The AFRSI used at the transition zone would be sufficient to withstand the maximum temperatures $\left(\sim 1030^{\circ} \mathrm{F}\right)$ shown in Fig. 22.

\section{Interpolated Result Verification}

An additional LATCH inviscid-boundary layer solution was run in order to test the validity of the interpolation scheme used to establish the time-dependent aerothermal environments shown here. The test case, identified as Case 8 in Table 1, was run for the flight condition at $334 \mathrm{sec}$ on the X1004601 trajectory. An inviscid solution at a Mach number of 6.17 and an AOA of 20.3 degrees was used as input to the LATCH code to establish turbulent heating levels over the vehicle. Figure 23 shows some representative heating time histories as predicted using the techniques described in this paper. The predictions are shown for three points along the

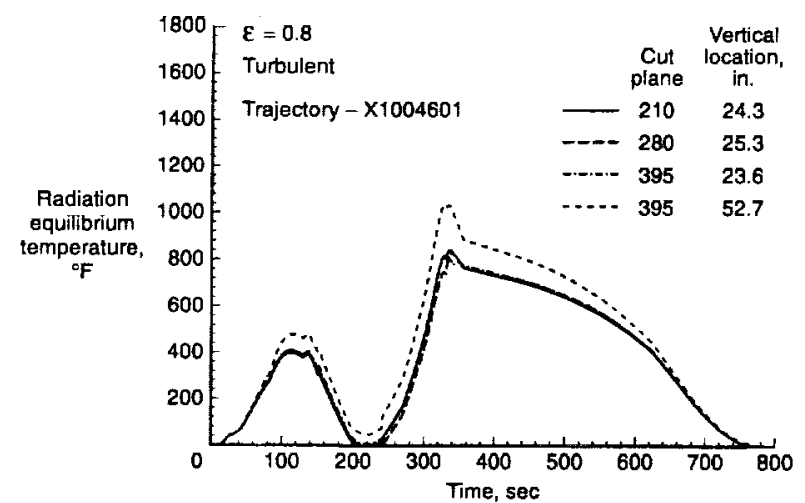

Fig. 22 Typical side surface temperature-time histories.

350-in. cut plane, including the windward and leeward centerline and a point near the leading edge of the strake. The predicted heating rates and radiation equilibrium temperatures are shown in Figs. 23(a) and 23(b) respectively. The results of the new LATCH solution at $334 \mathrm{sec}$ are also shown. Errors in heating rates of less than 10 percent are noted. The corresponding errors in temperature are significantly lower, less than 2 percent. Heat-transfer-coefficient errors (not shown) were noted to be less than $3 \%$. Similar results were observed for all other points examined. As noted previously, a portion of the error is introduced simply because the radiation equilibrium temperature computed along a trajectory will not be equivalent to one simply computed at a constant freestream condition. The interpolated results are shown to compare well with the LATCH solution generated at an additional flight condition, demonstrating the validity of the approach used in this study. Thus, the techniques employed here appear to enable prediction of timedependent aerothermal environments with a sufficient degree of accuracy for TPS design.

\section{Concluding Remarks}

This paper has described the methodology by which the aerothermal environments for the X-34 have been predicted in sufficient detail to allow design of the TPS such that the survivability, as well as the reusability, of the flight vehicle is ensured to a high degree of certainty. Initial estimates of the aerothermal environments, provided before any wind-tunnel or detailed computational data were available, are shown to be conservative. Engineering results, validated against both experimental data and viscous $\mathrm{N}-\mathrm{S}$ solutions, demonstrate good agreement. A combination of engineering methods, coupled with inviscid CFD solutions is used to generate the detailed time-dependent environments over the surface of the vehicle. The interpolated engineering values are shown 


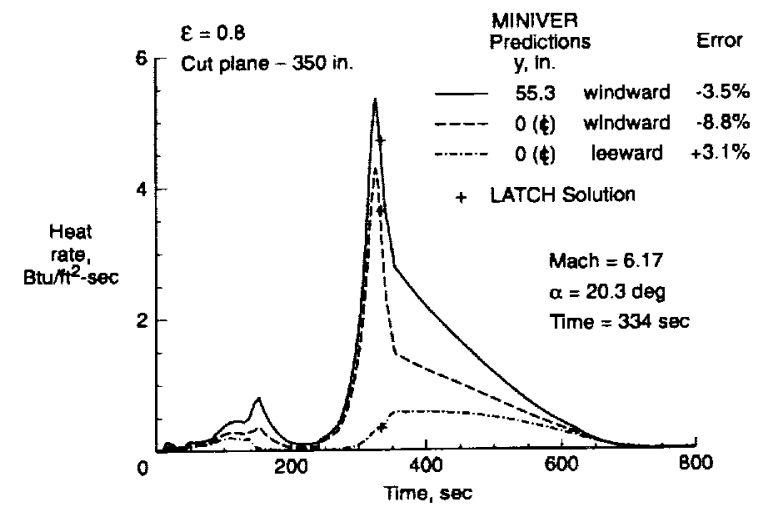

a) Heating rates.

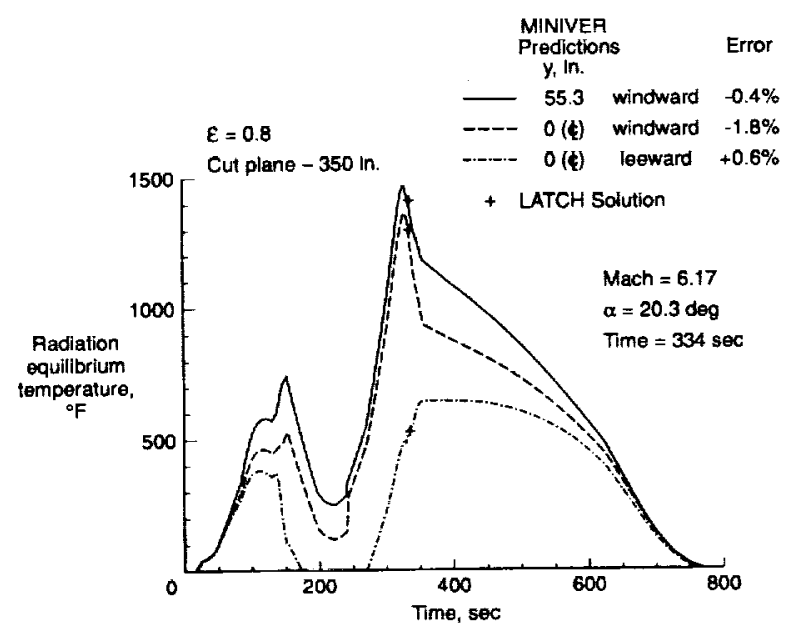

b) Temperatures.

\section{Fig. 23 Verification of MINIVER interpolation process.}

to be in good agreement with the more detailed results. However, it is noted that the selection of the cases for detailed solutions is quite critical to the success of the interpolation. In particular, the AOA and Mach-number conditions must be matched adequately and the conditions of peak windward and leeward surface heating must be captured. Selection of the peak heating conditions based on a cold wall value has been demonstrated to be inappropriate for vehicles such as the X-34 that operate in flight regimes where the recovery to wall enthalpy ratio is significant.

The results presented have been used to design and size the blanket TPS on the X-34. The method described was formulated to take optimal advantage of the strengths of the engineering and experimental techniques together with those of the detailed flowfield codes. Minimal computational resources and time were required to provide sufficiently accurate, time-dependent aerothermal envi- ronments to design the X-34 blanket TPS. This method could easily be automated and applied to many of the fast-paced programs which are typical in today's design environment. In doing so, the conservatism inherent to any TPS designed using engineering methods alone could be reduced, potentially decreasing the weight and improving the payload capability.

\section{References}

1 Freeman, D. C., Jr., Talay, T. A., and Austin, R. E., "Reusable Launch Vehicle Technology Program," IAF 96-V.4.01, Oct. 1996.

2 Milos, F. S. and Squire, T. H., "Thermal Structural Analysis of SIRCA Tile for X-34 Wing Leading Edge TPS," AIAA Paper 98-0883, Jan. 1998.

3 Carr, J., R. and Barber, D., "Blanket Design, Analysis and Testing for the X-34 Thermal Protection System," AIAA Paper 98-0884, Jan. 1998.

4 Palmer, G. and Polsky, S., "A Heating Analysis of the Nosecap and Leading Edges of the X-34 Vehicle," AIAA Paper 98-0878, Jan. 1998.

5 Merski, N. R., "Reduction and Analysis of Phosphor Thermography Data with the IHEAT Software Package," AIAA Paper 98-0712, Jan. 1998.

6 NASA, "X-34", NASA Research Announcement NRA 8-14, Mar. 1996.

7 NASA, "Reusable Launch Vehicle (RLV), Small Reusable Booster, X-34" Cooperative Agreement Notice CAN 8-2, Jan. 1995.

8 Engel, C. D. and Praharaj, S. C., "MINIVER Upgrade for the AVID System, Vol. I: LANMIN User's Manual," NASA CR-172212, Aug. 1983.

9 Baranowski, L. C., "Influence of Cross-Flow on Windward Centerline Heating," McDonnell Douglas Astronautics Co., Rept. MDC E0535, St. Louis, MO. Dec. 1971.

10 Schlichting, H., Boundary Layer Theory, 6th English ed., McGraw-Hill, New York, 1968.

11 Wurster, K. E., Zoby, E. V., and Thompson, R. A., "Flowfield and Vehicle Parameter Influence on Results of Engineering Aerothermal Methods," Journal of Spacecraft and Rockets, Vol. 28, No. 1, 1991, pp. 16-22.

12 Wurster, K. E. and Stone, H. W., "Aerodynamic Heating Environment Definition/Thermal Protection System Selection for the HL-20," Journal of Spacecraft and Rockets, Vol. 30, No. 5,1993, pp. 549-557.

13 Baumgartner, R. I. and Elvin, J. D., "Lifting Body - An Innovative RLV Concept," AIAA Paper 95-3531, Sep. 1995.

14 Advanced Technology Team, Access to Space Final Report, Vol. 1, Executive Summary, Jul. 1993. 
15 Hamilton, H. H., II, Greene, F. A., and DeJarnette, F. R., "Approximate Method for Calculating Heating Rates on Three-Dimensional Vehicles," Journal of Spacecraft and Rockets, Vol. 31, No. 3, 1994, pp. 345-354.

16 Zoby, E. V. and Simmonds, A. L., "Engineering Flowfield Method With Angle-of Attack Applications," Journal of Spacecraft and Rockets, Vol. 22, No. 4, 1985, pp. 398-405.

17 Zoby, E. V., "Approximate Heating Analysis for the Windward Symmetry Plane of Shuttle-like Bodies at Large Angle of Attack," Thermophysics of Atmospheric Entry, edited by T. E. Horton, Vol. 82 of Progress in Astronautics and Aeronautics, AIAA, 1982, pp. 229. 247.

18 Hamilton, H. H., DeJarnette, F. R., and Weilmuenster, K. J., "Application of Axisymmetric Analog for Calculating Heating in Three-Dimensional Flows," Journal of Spacecraft and Rockets, Vol. 24, No. 4, 1987, pp. 296-302.

19 Riley, C. J., Kleb, W. L., and Alter, S. J., "Aeroheating Predictions for X-34 Using an InviscidBoundary Layer Method," AIAA Paper 98-0880, Jan. 1998.

20 Hamilton, H. H., II, Weilmuenster, K. J., and Horvath, T. J., "Computational/Experimental Aeroheating Predictions for X-33 Phase II Vehicle," AIAA Paper 98-0869, Jan. 1998.

21 Candler, G. V., Wright, M. J., and McDonald, J. D., "Data-Parallel Lower-Upper Relaxation Method for Reacting Flows," AIAA Journal, Vol. 32, No. 12, 1994, pp. 2380-2386.

22 Wright, M. J., Candler, G. V., and Prampolini, M., "Data-Parallel Lower-Upper Relaxation Method for the Navier-Stokes Equations,"AIAA Journal, Vol. 34, No 7., 1996, pp. 1371-1377.

23 Gnoffo, P. A., "Upwind-Biased, Point-Implicit Relaxation Strategies for Viscous, Hypersonic Flows," AIAA Paper 89-1972, 1989.

24 Gnoffo, P. A., "An Upwind-Biased, PointImplicit Relaxation Algorithm for Viscous, Compressible Perfect-Gas Flows," NASA TP 2953, Feb. 1990.

25 Kleb, W. L., Wood, W. A., Gnoffo, P. A., and Alter, S. J., "Computational Aeroheating Predictions for X-34," AIAA Paper 98-0879, Jan. 1998.

26 Gnoffo, P. A., Weilmuenster, K. J., and Alter, S. J., "Multi-block Analysis for Shuttle Orbiter Re-Entry Heating From Mach 24 to Mach 12,"Journal of Spacecraft and Rockets, Vol. 31, No. 3, 1994, pp. 367-377.
27 Greene, F. A., Weilmuenster, K. J., and Micol, J. R., "Predicted Aerodynamics for a Proposed Personnel launch Vehicle," AIAA Paper 90-1668, Jun. 1990.

28 Wood, W. A., Riley, C. J., and Cheatwood, F. M., "Reentry-F Flowfield Solutions at 80,000 ft," NASA TM 112856, May 1997.

29 Buck, G. M., "Automated Thermal Mapping Techniques Using Chromatic Image Analysis," NASA TM 101554, Apr. 1989.

30 Buck, G. M., "Surface Temperature/Heat transfer Measurement Using A Quantitative Phosphor Thermography System," AIAA Paper 91-0064, Jan. 1991.

31 Merski, N. R., "A Relative-Intensity Two-Color phosphor Thermography System," NASA TM 104123, Sep. 1991.

32 Berry, S. A., Horvath, T. J., DiFulvio, M., Glass, C. E., and Merski, N. R., "X-34 Experimental Aeroheating at Mach 6 and 10," AIAA Paper 98-0881, Jan. 1998.

33 Micol, J. R., "Hypersonic Aerodynamic/ Aerothermodynamic Testing Capabilities at Langley Research Center: Aerothermodynamic Facilities Complex," AIAA Paper 95-2107, Jun. 1995.

34 TPSX Database, NASA Ames Research Center, 1997.

35 Rivell, T., "Preliminary Design of the Thermal Protection System for the X-34 Reusable Launch Vehicle: SIRCA-15F Tiles," ARC Report, Feb. 1997.

36 Adams, J. C., Jr., "Implicit Finite-Difference Analysis of Compressible laminar, Transitional, and Turbulent Boundary Layers Along the Windward Streamline on a Sharp Cone at Incidence," AEDC-TR71-235, Dec. 1971.

37 Fay, J. A., and Riddell, F. R., "Theory of Stagnation-Point Heat Transfer in Dissociated Air," Journal of Aeronautical Sciences, Vol. 25, No. 2, 1958, pp. 73-85,121.

38 Brauer, G. L., Cornick, D. E., and Stevenson, T., "Capabilities and Applications of the Program to Optimize Simulated Trajectories (POST)," NASA CR2770, Feb. 1977. 
